Research Article

\title{
Numerical Analysis on Shear Behavior of Joints under Low Confining and Eccentric Loads
}

\author{
Gongfa Chen, Zhuangcheng Fang, Shaodi Wang, Haibo Jiang ${ }^{D}$, and Hualian Liang
}

School of Civil and Transportation Engineering, Guangdong University of Technology, Guangzhou Higher Education Mega Center, Guangzhou 510006, China

Correspondence should be addressed to Haibo Jiang; hbjiang@gdut.edu.cn

Received 11 October 2018; Revised 18 February 2019; Accepted 11 March 2019; Published 30 April 2019

Academic Editor: Claudio Mazzotti

Copyright (c) 2019 Gongfa Chen et al. This is an open access article distributed under the Creative Commons Attribution License, which permits unrestricted use, distribution, and reproduction in any medium, provided the original work is properly cited.

\begin{abstract}
The joints of precast concrete segmental beams (PCSBs), which are in complex stress status and susceptible to failure, are very important parts of the structure. In this paper, a finite element model was established to study the shear performance of singlekeyed joints. The plastic damage model was used to simulate the cracking of specimens. Three types of single-keyed joints were investigated, including the dry joint with normal concrete (NC), dry joint with steel fiber-reinforced concrete (SFRC), and epoxied joint with NC. The cracking pattern, ultimate shear strength, and load-displacement curve for these specimens were obtained. Based on these numerical simulation models, extended analyses in terms of low confining pressures and eccentric loads were performed. It has been found that the influence of fiber-reinforced concrete should be considered. The ultimate shear strength of specimens reduced with the reduction of confining pressure. When an eccentric load was applied, a lower shear capacity would be obtained. Under the low confining stress, the AASHTO LRFD 2014 provision underestimated the shear strength of single-keyed dry joints with both NC and SFRC, while the shear capacity of single-keyed dry joints with both NC and SFRC has been overestimated under the eccentric loads.
\end{abstract}

\section{Introduction}

Precast concrete segmental beams (PCSBs), which are assembled from precast segments through posttensioned prestressing, are becoming more and more popular in modern bridge construction. With the advantages of rapid construction, good durability, and low life cycle cost, PCSBs have solved lots of problems in design, construction, and maintenance for bridge engineering. Previous studies have found that the shear behavior of joints in PCSBs was crucial for the safety of PCSBs. Hence, the design, construction, and quality of joints should be well controlled. Nowadays, two types of joints (dry joints and epoxy joints) have been widely used in engineering projects. For the former one, the joint is attached closely without any adhesive; for the latter one, epoxy resin is coated on the surface of the joints before assembling of PCSBs. Although dry joints and epoxy joints have many advantages, their shear performance is far inferior to that of monolithic joints [1]. Therefore, it is significant to properly design keyed joints with better shear performance and better structure. The shear performance of joints has been investigated under the disadvantageous condition of low confining stress and eccentric loading.

Lower horizontal confining pressure and larger eccentric loading, which may occur in bridge engineering, weaken the shear capacity of joints greatly. Usually, the capacity of joints was divided into two portions, i.e., the friction action of joints and shear resistance provided by the key. As shown in Figure 1, the bottom of joints is more likely to open in low confining pressure. This decreases the ultimate load of joints because of the weakening of both friction and shear resistance. When a larger eccentric load is applied, the additional bending moment formed by the eccentric load will be offset or even larger than that produced by horizontal restraint force. In this case, the joint will be opened, which results in the decrease of the shear capacity of joints. Besides, 

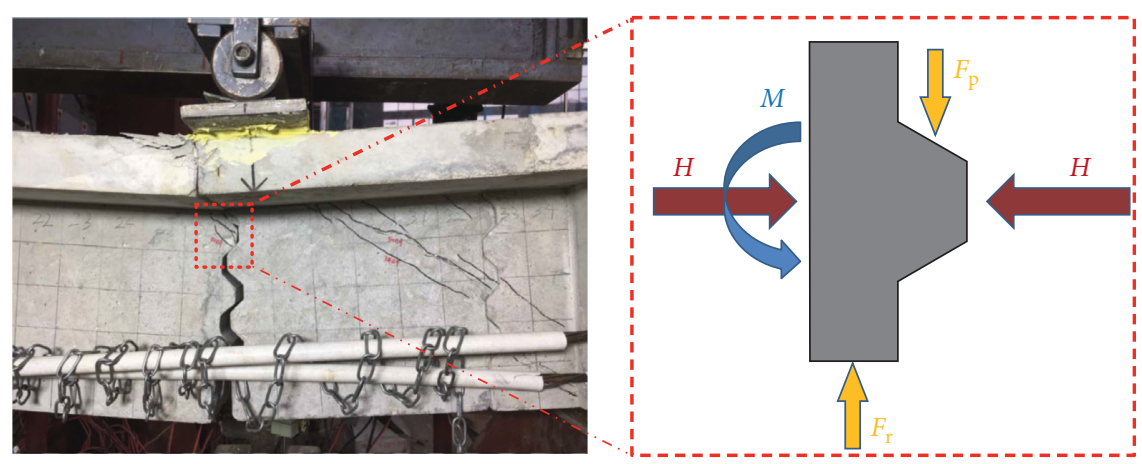

Figure 1: Opening and forces on the joint under shear.

the prestress applied in fabrication and assembling, or the construction error at prefabrication, will also lead to the low confining stress on the shear keyed joints. This has greatly influenced construction of bridge engineering, yet few studies focused on it.

Recently, several investigations focused on the experimental and theoretical study of shear behavior of joints in PCSBs. The shear performance of epoxied joints was better than that of dry joints, even close to that of cast-in-place monolithic joints [1]. However, more brittle failure mode was observed for epoxied joints compared with dry joints [2]. Increasing the number of keys improved the shear strength of joints, but the strength of multikeyed dry joints was less than that of the total single-keyed dry joints with the same quantity [3]. Changing the key geometry may also greatly influence the shear performance of joints [4]. Additionally, higher horizontal confining pressure or using a more suitable material (e.g., SFRC) also increased the strength of dry joints effectively. The limitation of current design codes such as AASHTO specifications and Spanish provision was investigated $[5,6]$. Thus, some design formulas were proposed [6]. Nevertheless, a large amount of labor, resources, or equipment or a big place was demanded for experimental research. Even for theoretical analysis, necessary experimental data were required for verification.

Because of the limitation of experimental tests and theoretical analysis, numerical simulation became more and more popular to predict the stress, strain, energy, or damage for shear behavior of joints. Compared with experimental results, the numerical model was valid so that extended analysis can be conducted with the model [7]. Thus, some parameters that were hard to study by experimental methods can be investigated by numerical models [8-11]. Generally, the existing experimental, theoretical, and numerical investigations mainly focused on dry joints, but there are few studies which focused on epoxied joints or dry joints with SFRC which have better shear resistance comparatively. In addition, confining pressure greatly influences the shear capacity of joints.

In this paper, finite element simulations were performed, and the numerical model was validated by the experimental results from the study of Jiang et al. [12] and Zhou and Mickleborough [5]. In order to study the shear failure performance of joints under low horizontal confining pressure and eccentric loads, extended parametric analyses were performed. Finally, the parametric analysis results were compared with AASHTO provision. The results of this paper will provide important reference for experimental investigation, theoretical research, or engineering practice.

\section{Experimental Model}

2.1. Experimental Data. In order to improve the validity of the finite element model, previous experimental studies were referred, including the experimental results of monolithic joints with NC [12], single-keyed dry joints with NC [12], single-keyed dry joints with SFRC [12], and single-keyed epoxied joints with NC [5]. The initial nomenclatures and parameters for each specimen are listed in Table 1. To get a unified format, all the specimens were renamed, as shown in Table 1. The redefined specimen designation indicated the type of joint, the type of concrete, and the confining pressure.

2.2. Experimental Model Size. Details of experimental specimens and reinforcements are shown in Figure 2. It can be seen that the dimensions of specimens of monolithic joints were $540 \mathrm{~mm} \times 340 \mathrm{~mm} \times 100 \mathrm{~mm}$, the same as those of single-keyed dry joint specimens, while the dimensions of single-keyed epoxied specimens were $620 \mathrm{~mm} \times 500 \mathrm{~mm}$ $\times 250 \mathrm{~mm}$, larger than those of single-keyed dry joints.

\section{Numerical Model}

3.1. Plastic Damage Constitutive Model of Concrete. In this study, the concrete damaged plasticity (CDP) model was used to simulate the elastic-plastic behavior of concrete in ABAQUS 6.14. There were two types of failure modes, i.e., the tensile cracking failure and compressive crushing failure. For the finite element model in this paper, the dilation angle, the eccentricity of flow, and the viscosity coefficient were set as $31,0.1$, and 0.0001 , respectively. Additionally, the ratio of uniaxial strength to biaxial strength $\left(f_{\mathrm{b} 0} / f_{\mathrm{c} 0}\right)$ was 1.16.

As CDP cannot describe the initiation and development of fractures, to simulate the fracture of concrete, it was 
TABle 1: Experimental results from the study by Jiang et al. [12] and Zhou and Mickleborough [5].

\begin{tabular}{|c|c|c|c|c|c|c|}
\hline $\begin{array}{l}\text { Specimen } \\
\text { (initial } \\
\text { designation) }\end{array}$ & $\begin{array}{c}\text { Specimen } \\
\text { (redefined } \\
\text { designation) }\end{array}$ & Type of joint & Type of concrete & $\begin{array}{c}f_{c}^{\prime} \\
(\mathrm{MPa})\end{array}$ & $\begin{array}{c}\text { Confining } \\
\text { pressure } \\
(\mathrm{MPa})\end{array}$ & $\begin{array}{l}\text { Experimental } \\
\text { shear } \\
\text { strength }(\mathrm{kN})\end{array}$ \\
\hline M0-H6-N-0.5 & M0-C50-0.5 & Monolithic & Normal concrete & 50.32 & 0.5 & 176.60 \\
\hline M0-H6-N-1.0 & M0-C50-1.0 & Monolithic & Normal concrete & 50.32 & 1.0 & 199.30 \\
\hline M0-H6-N-2.0 & M0-C50-2.0 & Monolithic & Normal concrete & 50.32 & 2.0 & 213.10 \\
\hline K1-H6-N-0.5 & K1-C50-0.5 & Single-keyed dry joint & Normal concrete & 49.05 & 0.5 & 97.40 \\
\hline K1-H6-N-1.0 & K1-C50-1.0 & Single-keyed dry joint & Normal concrete & 49.05 & 1.0 & 118.90 \\
\hline K1-H6-N-2.0 & K1-C50-2.0 & Single-keyed dry joint & Normal concrete & 49.05 & 2.0 & 137.50 \\
\hline K1-S6-60-0.5 & K1-S50-0.5 & Single-keyed dry joint & $\begin{array}{l}\text { Steel fiber-reinforced } \\
\text { concrete }\end{array}$ & 53.10 & 0.5 & 110.80 \\
\hline K1-S6-60-1.0 & K1-S50-1.0 & Single-keyed dry joint & $\begin{array}{l}\text { Steel fiber-reinforced } \\
\text { concrete }\end{array}$ & 53.10 & 1.0 & 135.70 \\
\hline K1-S6-60-2.0 & $\mathrm{K} 1-\mathrm{S} 50-2.0$ & Single-keyed dry joint & $\begin{array}{l}\text { Steel fiber-reinforced } \\
\text { concrete }\end{array}$ & 53.10 & 2.0 & 162.40 \\
\hline M1-E1-K1 & EA1-C50-1.0 & $\begin{array}{l}\text { Single-keyed epoxied joint } \\
\text { (1 mm thick epoxy) }\end{array}$ & Normal concrete & 53.10 & 1.0 & 273.00 \\
\hline M2-E1-K1 & EA1-C50-2.0 & $\begin{array}{l}\text { Single-keyed epoxied joint } \\
\text { (1 mm thick epoxy) }\end{array}$ & Normal concrete & 53.10 & 2.0 & 405.00 \\
\hline M3-E1-K1 & EA1-C50-3.0 & $\begin{array}{l}\text { Single-keyed epoxied joint } \\
\text { (1 mm thick epoxy) }\end{array}$ & Normal concrete & 57.60 & 3.0 & 474.00 \\
\hline M1-E2-K1 & EB1-C50-1.0 & $\begin{array}{l}\text { Single-keyed epoxied joint } \\
\text { (2 mm thick epoxy) }\end{array}$ & Normal concrete & 53.50 & 1.0 & 251.00 \\
\hline M2-E2-K1 & EB1-C50-2.0 & $\begin{array}{l}\text { Single-keyed epoxied joint } \\
\text { ( } 2 \mathrm{~mm} \text { thick epoxy) }\end{array}$ & Normal concrete & 53.50 & 2.0 & 377.00 \\
\hline M3-E2-K1 & EB1-C50-3.0 & $\begin{array}{l}\text { Single-keyed epoxied joint } \\
\text { (2 } \mathrm{mm} \text { thick epoxy) }\end{array}$ & Normal concrete & 55.20 & 3.0 & 488.00 \\
\hline M1-E3-K1 & EC1-C50-1.0 & $\begin{array}{l}\text { Single-keyed epoxied joint } \\
\text { ( } 3 \mathrm{~mm} \text { thick epoxy) }\end{array}$ & Normal concrete & 56.60 & 1.0 & 265.00 \\
\hline M2-E3-K1 & EC1-C50-2.0 & $\begin{array}{l}\text { Single-keyed epoxied joint } \\
\text { ( } 3 \mathrm{~mm} \text { thick epoxy) }\end{array}$ & Normal concrete & 59.60 & 2.0 & 318.00 \\
\hline M3-E3-K1 & EC1-C50-3.0 & $\begin{array}{l}\text { Single-keyed epoxied joint } \\
\text { ( } 3 \mathrm{~mm} \text { thick epoxy) }\end{array}$ & Normal concrete & 56.20 & 3.0 & 355.00 \\
\hline
\end{tabular}

Note: $f_{\mathrm{c}}^{\prime}$ is the cylinder compressive strength of concrete at the test day.

assumed that the fracture was initiated when the tensile strain in the tension stiffening stage $\varepsilon_{0}$ was larger than ten times of standard concrete failure strain $\varepsilon_{c, r}[10]$. When reaching the ultimate tensile strain, the concrete has lost the resistance to cracking.

3.2. Constitutive Relationship of Concrete. According to the Chinese code for the design of concrete structures [13], the modulus of elasticity $E_{\mathrm{c}}$ and Poisson's ratio $v_{\mathrm{c}}$ of concrete were determined by using the following formula:

$$
\begin{aligned}
& E_{\mathrm{c}}=\frac{10^{5}}{2.2+\left(34.7 / f_{\mathrm{cm}}\right)}, \\
& v_{\mathrm{c}}=0.2
\end{aligned}
$$

where $f_{\mathrm{cm}}$ is the average value of compressive strength of concrete. This code [13] also provided the stress-strain relationship of concrete to describe the behaviors of concrete under uniaxial tension and compression. The constitutive relationship of concrete under uniaxial compression is expressed as

$$
\begin{aligned}
\sigma & =\left(1-d_{\mathrm{c}}\right) E_{\mathrm{c}} \varepsilon, \\
d_{\mathrm{c}} & = \begin{cases}1-\frac{\rho_{\mathrm{c}} n}{n-1+x^{n}} x, & x \leq 1, \\
1-\frac{\rho_{\mathrm{c}}}{\alpha_{\mathrm{c}}(x-1)^{2}+x}, & x>1,\end{cases} \\
x & =\frac{\varepsilon}{\varepsilon_{\mathrm{c}, \mathrm{r}}}, \\
\rho_{\mathrm{c}} & =\frac{f_{\mathrm{c}, \mathrm{r}}}{E_{\mathrm{c}} \varepsilon_{\mathrm{c}, \mathrm{r}}}, \\
n & =\frac{E_{\mathrm{c}} \varepsilon_{\mathrm{c}, \mathrm{r}}}{E_{\mathrm{c}} \varepsilon_{\mathrm{c}, \mathrm{r}}-f_{\mathrm{c}, \mathrm{r}}},
\end{aligned}
$$




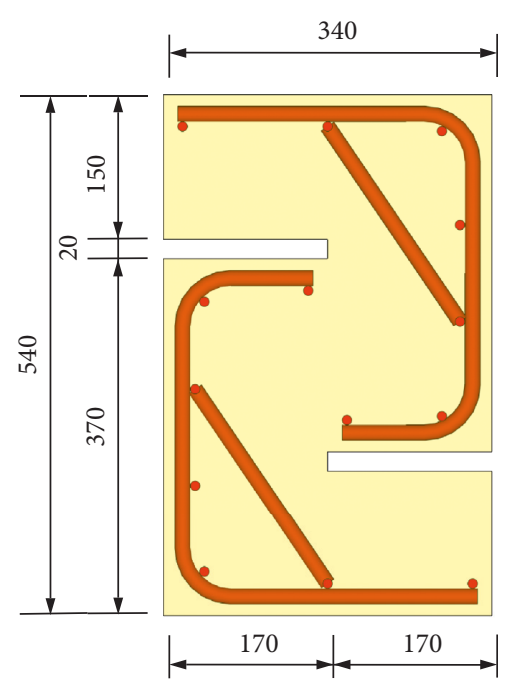

(a)

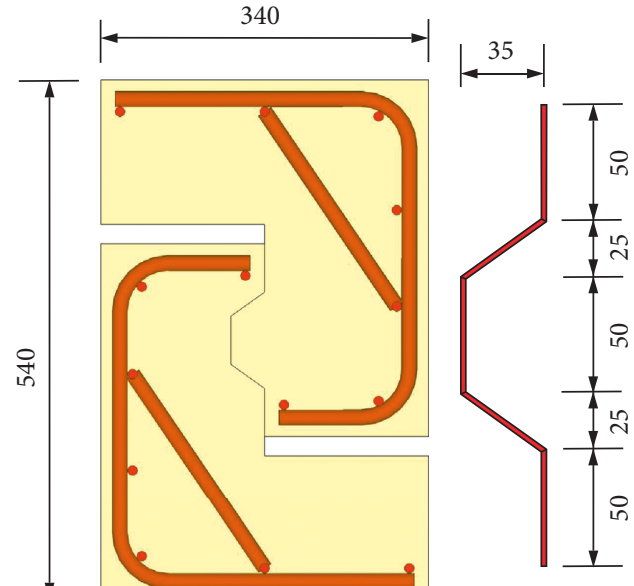

(b)

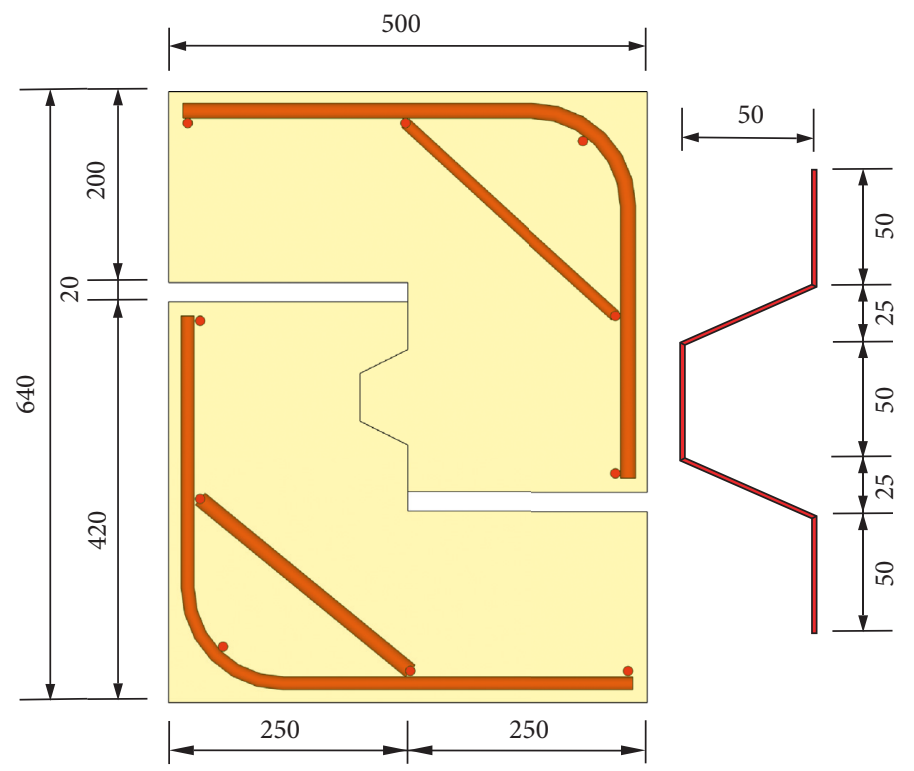

(c)

Figure 2: Details of specimen dimensions and reinforcement (all dimensions are in $\mathrm{mm}$ ). (a) Monolithic joint. (b) Single-keyed dry joint. (c) Single-keyed epoxied joint.

where $d_{\mathrm{c}}$ is the damage evolution parameter of concrete under uniaxial compression, $\varepsilon$ is the compressive strain of concrete, $\alpha_{\mathrm{c}}$ is the parameter for the descent segment in a constitutive relationship of concrete under uniaxial compression, $f_{c, r}$ is the uniaxial compressive strength of concrete and takes the average value of the compressive strength of concrete in this paper, and $\varepsilon_{c, r}$ is the peak compressive strain corresponding to $f_{c, r}$. For different compressive strengths shown in Table 1, corresponding values of $\alpha_{\mathrm{c}}$ and $\varepsilon_{c, r}$ were acquired through linear interpolation based on the recommended information listed in Table 2.

The constitutive relationship of the concrete under uniaxial tension is expressed as

$$
\begin{aligned}
& \sigma=\left(1-d_{\mathrm{t}}\right) E_{\mathrm{c}} \varepsilon, \\
& d_{\mathrm{t}}=\left\{\begin{array}{l}
1-\rho_{\mathrm{t}}\left(1.2-0.2 x^{5}\right), \quad x \leq 1, \\
1-\frac{\rho_{\mathrm{t}}}{\alpha_{\mathrm{t}}(x-1)^{1.7}+x}, \quad x>1,
\end{array}\right. \\
& x=\frac{\varepsilon}{\varepsilon_{\mathrm{t}, \mathrm{r}}}, \\
& \rho_{\mathrm{t}}=\frac{f_{\mathrm{t}, \mathrm{r}}}{E_{\mathrm{t}} \varepsilon_{\mathrm{t}, \mathrm{r}}},
\end{aligned}
$$


TABLE 2: Parameter values of stress-strain curves of concrete under uniaxial compression.

\begin{tabular}{lccccccccccccc}
\hline$f_{\mathrm{c}, \mathrm{r}}(\mathrm{MPa})$ & 20 & 25 & 30 & 35 & 40 & 45 & 50 & 55 & 60 & 65 & 70 & 75 & 80 \\
$\alpha_{\mathrm{c}}$ & 0.74 & 1.06 & 1.36 & 1.65 & 1.94 & 2.21 & 2.48 & 2.74 & 3.00 & 3.25 & 3.50 & 3.75 & 3.99 \\
$\varepsilon_{\mathrm{c}, \mathrm{r}}\left(10^{-6}\right)$ & 1470 & 1560 & 1640 & 1720 & 1790 & 1850 & 1920 & 1980 & 2030 & 2080 & 2130 & 2090 & 2240 \\
\hline
\end{tabular}

where $d_{\mathrm{t}}$ is the damage evolution parameter of the concrete under uniaxial tension, $\alpha_{t}$ is the parameter for the descent segment in a constitutive relationship of concrete under uniaxial tension, $f_{\mathrm{t}, \mathrm{r}}$ is the uniaxial tension strength of concrete and takes the average value of the tension strength of concrete in this paper, and $\varepsilon_{\mathrm{t}, \mathrm{r}}$ is the peak tensile strain corresponding to $f_{\mathrm{t}, \mathrm{r}}$. Due to the lack of experimental results, the tension strength for different types of normal concrete was then taken as $10 \%$ of its compressive strength, which has also been adopted in the study by Shamass et al. [10]. Similarly, the values of $\alpha_{\mathrm{t}}$ and $\varepsilon_{\mathrm{t}, \mathrm{r}}$ were calculated with linear interpolation based on the parameter values depicted in Table 3.

3.3. Constitutive Relationship of SFRC. Considering the influence of fiber factor $F[14]$, the damage constitutive relationship of SFRC under uniaxial compression could be shown as follows:

$$
\begin{aligned}
& \sigma=E \varepsilon \exp \left[-\left(\frac{\varepsilon}{0.00052 F+0.0025}\right)^{(-1.091 F+1.983)}\right], \\
& F=\beta V_{\mathrm{f}} \frac{l_{\mathrm{f}}}{d_{\mathrm{f}}},
\end{aligned}
$$

where $E$ is the modulus of elasticity of SFRC without damage; $\varepsilon$ is the compressive strain of SFRC; $\beta$ is the bond coefficient of the fiber, which is related to the geometric properties of the fiber and taken as 1.2 in this study; and $V_{\mathrm{f}}, l_{\mathrm{f}}$, and $d_{\mathrm{f}}$ are the volume fraction, length, and diameter of the fiber, respectively. Actually, this is a quite simplified way to derive the tensile behavior of SFRC. Some sort of inverse analysis based on bending tests should be used to derive the tensile properties of SFRC materials if possible.

3.4. Constitutive Relationship of Epoxy. For epoxied joint specimens in this study, the bonding strength of interface between the epoxy and concrete was $22 \mathrm{MPa}$, which was much higher than the tensile strength of concrete [5]. On the contrary, both the compressive and tensile strengths of the epoxy were much higher than those of concrete. As a result, all the epoxied specimens failed in shear or in tensile of concrete. To be simple, the epoxy in the finite element model was set as an elastic material with the elastic modulus of 4.826 GPa and Poisson's ratio of 0.2, respectively [9].

3.5. Constitutive Relationship of Steel Rebar. An elasticplastic bilinear model was established to represent the constitutive relationship of the reinforcement. This stressstrain relationship could be expressed as
TABLE 3: Parameter values of uniaxial tensile stress-strain curves of concrete.

\begin{tabular}{lccccccc}
\hline$f_{\mathrm{t}, \mathrm{r}}(\mathrm{MPa})$ & 1.0 & 1.5 & 2.0 & 2.5 & 3.0 & 3.5 & 4.0 \\
$\alpha_{\mathrm{t}}$ & 0.31 & 0.70 & 1.25 & 1.95 & 2.81 & 3.82 & 5.00 \\
$\varepsilon_{\mathrm{t}, \mathrm{r}}\left(10^{-6}\right)$ & 65 & 81 & 95 & 107 & 118 & 128 & 137 \\
\hline \multicolumn{6}{c}{$\sigma_{\mathrm{s}}$} & $=E_{\mathrm{s}} \varepsilon_{\mathrm{s}}, \quad \varepsilon_{\mathrm{s}} \leq \varepsilon_{\mathrm{y}}$, \\
& $\sigma_{\mathrm{s}}=f_{\mathrm{y}}, \quad \varepsilon_{\mathrm{s}}>\varepsilon_{\mathrm{y}}$,
\end{tabular}

where $E_{\mathrm{s}}$ is the elastic modulus of the steel rebar, $f_{\mathrm{y}}$ is the yield strength of the reinforcement, and $\varepsilon_{\mathrm{y}}$ is the strain at yield strength of the steel rebar.

3.6. Finite Element Modelling. A three-dimensional solid model was used for simulation in this paper (Figure 3 ). In the model, both the concrete and epoxy layer were simulated as solid elements (C3D8R), while the reinforcement was simulated as a truss element (T3D2). Finer mesh was used for the most critical castellated keyed area. Especially, surface-to-surface contact interaction was adopted for the numerical model, using the finite sliding analysis procedure. Moreover, the contact surface associated with the lower portion (i.e., female part) was taken as the master surface, while the other one of the upper male section was defined as the slave surface. Based on the experimental results $[5,12]$, the friction coefficient between concrete surfaces was assumed as 0.6 for keyed joint specimens. Particularly, material nonlinear and contact nonlinear analyses were used in the numerical simulations. Additionally, all the translational degrees of freedom for the bottom surface were restricted.

For the loading process, constant uniform pressure was applied on both sides of the model to simulate the horizontal confining stress. The confining stress values were $0.5,1.0$, and 2.0 MPa, respectively, covering the monolithic or singlekeyed dry joint area of $200 \times 100 \mathrm{~mm}^{2}$, as per Jiang et al. [12]. Similarly, for the case of single-keyed epoxied joints, the confining pressure was applied covering a keyed area of $200 \times 100 \mathrm{~mm}^{2}$. The confining stress values were $1.0,2.0$, and 3.0 MPa, respectively, as per Zhou and Mickleborough [5]. The vertical displacement-controlled loading was then applied on top of the model, which was simulated by creating a boundary condition moving vertically downward, with a prescribed displacement rate $(0.3 \mathrm{~mm} / \mathrm{min})$ as adopted in the experiments done by Jiang et al. [12] and Zhou and Mickleborough [5].

\section{Simulated Results and Discussion}

The simulated results and experimental ones are compared on shear capacity (Table 4), load-displacement curves (Figure 4), and cracking development process (Figure 5). 


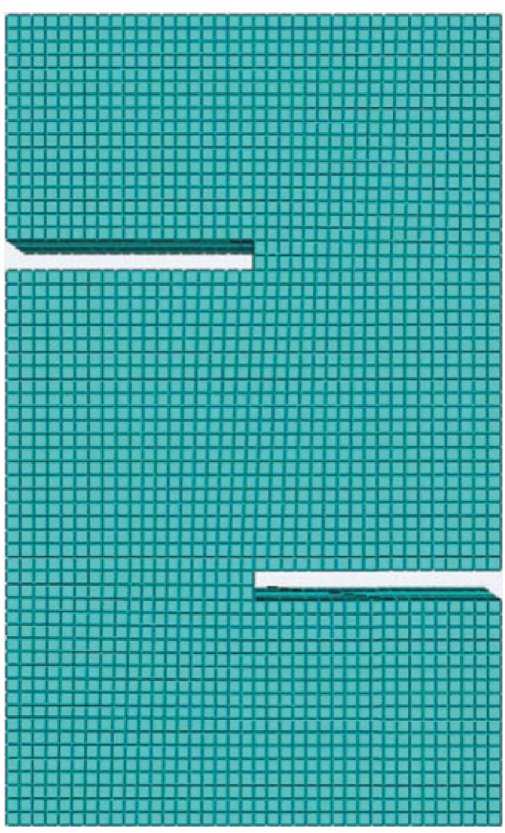

(a)

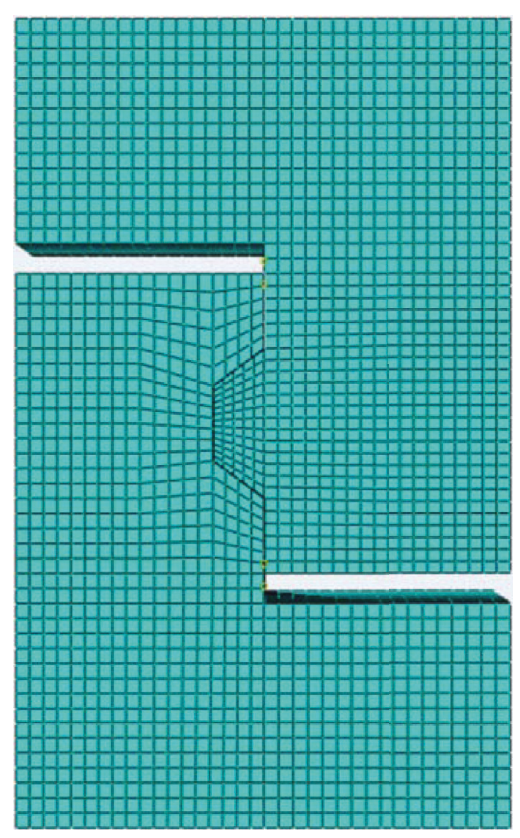

(b)

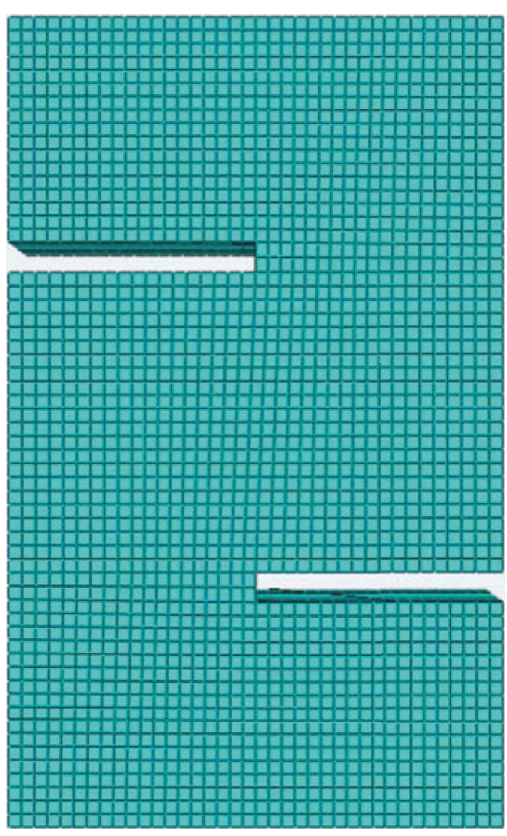

(c)

Figure 3: Meshing of a three-dimensional finite element model. (a) Monolithic joint. (b) Single-keyed dry joint. (c) Single-keyed epoxied joint.

TABLE 4: Comparison of experimental and simulated shear capacities for specimens with different joints.

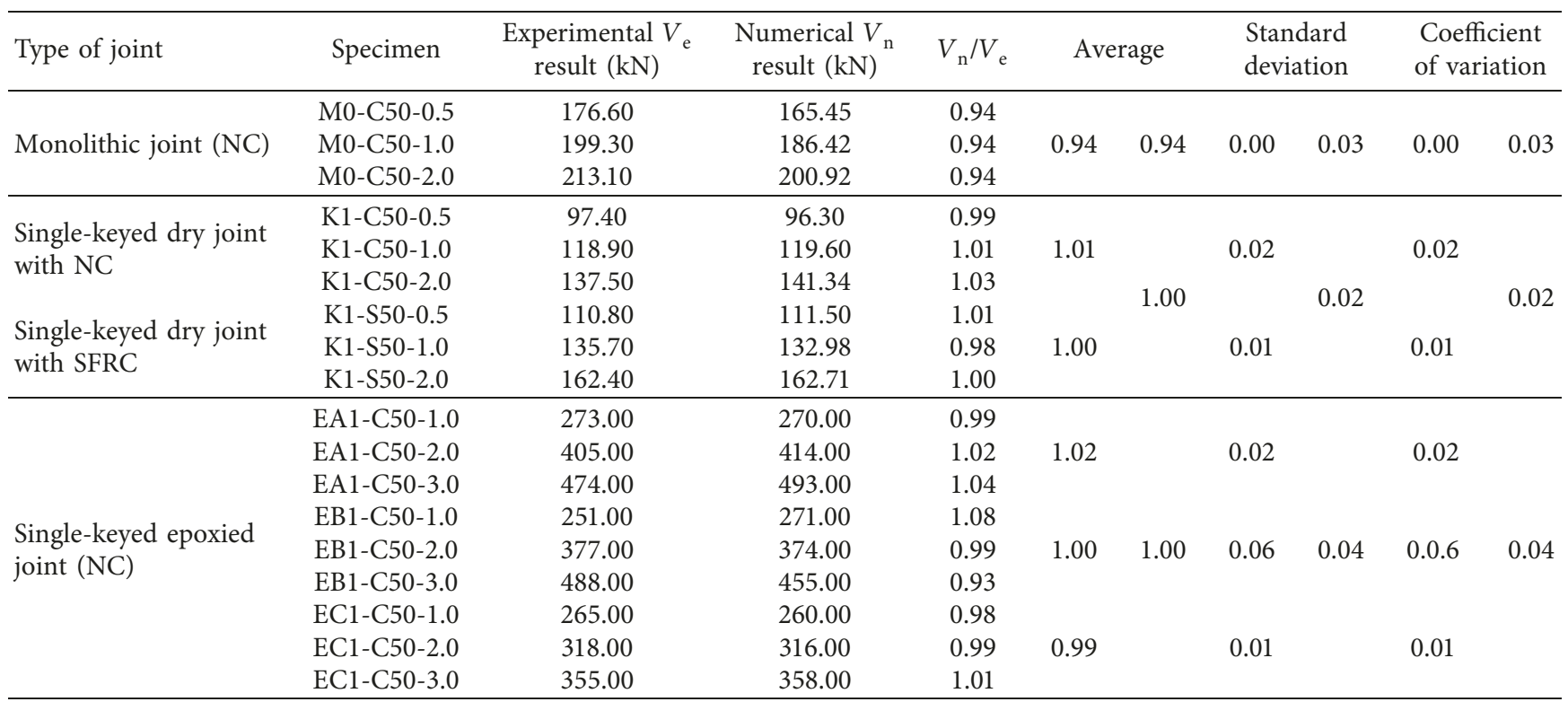

Note: $\mathrm{NC}=$ normal concrete; $\mathrm{SFRC}=$ steel fiber-reinforced concrete.

Especially, all the slippages of the joint were taken as the average deflections of that at the top and the bottom surface of the joint, which was consistent with the location of vertical LVDTs in the previous experimental study $[5,12]$.

4.1. Comparison of Shear Capacity. Table 4 lists the experimental and simulated shear capacities for specimens with different types of joints. For monolithic joint specimens, the values of average and standard deviation of ratio of numerical results to experimental ones $\left(V_{\mathrm{n}} / V_{\mathrm{e}}\right)$ were 0.94 and 0.03 , respectively. This indicated that the numerical results for specimens with monolithic joints gave an acceptable conservative prediction. For single-keyed dry joints (NC or SFRC) and single-keyed epoxied joints (with the epoxy thickness of $1 \mathrm{~mm}, 2 \mathrm{~mm}$, or $3 \mathrm{~mm}$ ), the ultimate shear capacity obtained by finite element analysis was in good agreement with that by the test. The average value of $V_{\mathrm{n}} / V_{\mathrm{e}}$ 


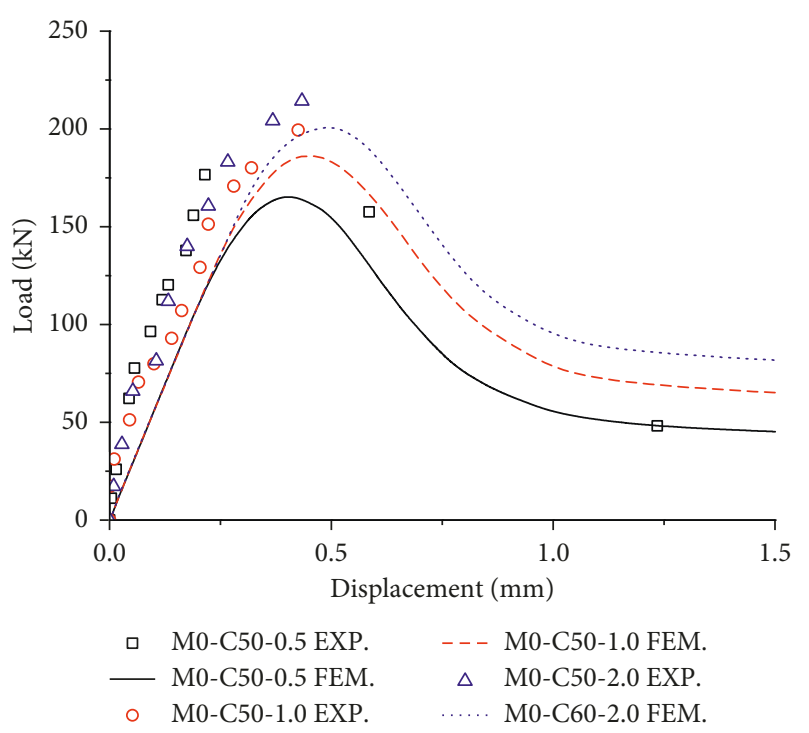

(a)

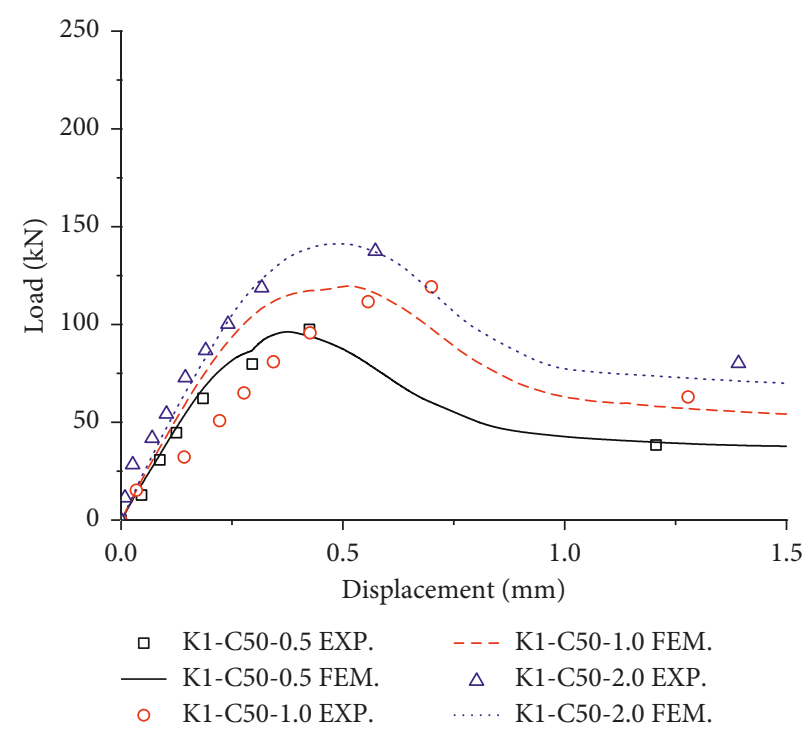

(b)

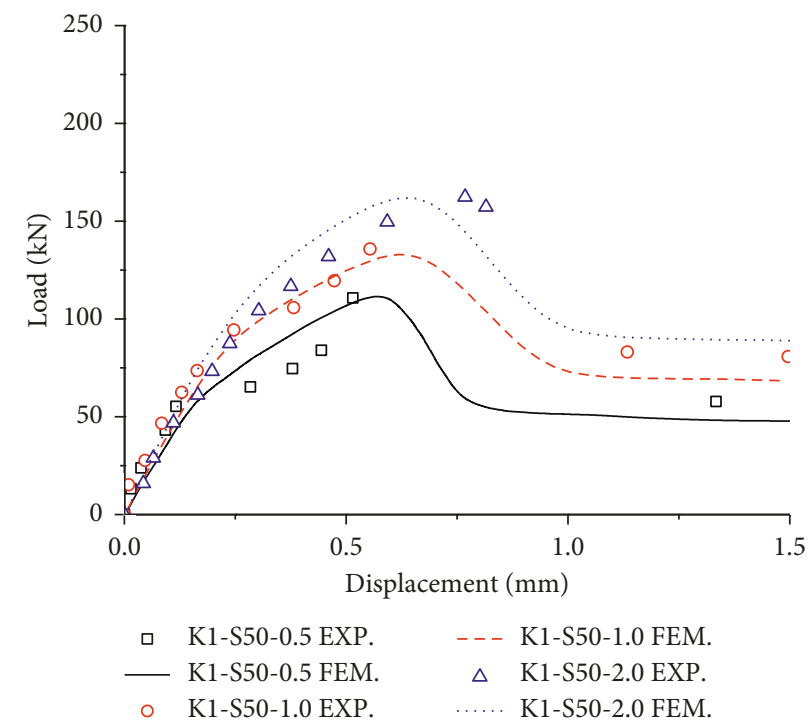

(c)

Figure 4: Comparison of experimental and simulated load-displacement curves for specimens with different joints. (a) Monolithic joint. (b) Single-keyed dry joint with NC. (c) Single-keyed dry joint with SFRC.

for both the dry joint specimens and epoxied joint specimens was 1.00 , and the standard deviation of $V_{\mathrm{n}} / V_{\mathrm{e}}$ for dry joint specimens and epoxied joint specimens was 0.02 and 0.04 , respectively.

4.2. Comparison of Load-Displacement Curves. Figure 4 shows the experimental and simulated load-displacement curves for specimens with different joints. The experimental results (EXP) were presented as the scattered dots, while the finite element model (FEM) analysis results were shown as the dashed or solid line. It can be found that the simulated curves and the test data points were approximately similar. For better understanding, the curve can be divided into three portions.
4.2.1. Portion I: Ascending Phase. In the beginning of this stage, all of the materials were in the linear elastic state and the relative displacement of the specimen increased with the increase of applied loading. After the first crack occurred, the stiffness of the specimen diminished, causing the slope of the load-displacement curve decrease gradually. At the end of this stage, the slope of the curve approached zero and the ultimate shear capacity was reached at the same time.

It can be found that the slope of test curves for monolithic joints was slightly larger than that of the simulation curves. This may be resulted from the difference between the adopted constitutive relation and the real stressstrain relation for concrete, which highlighted the importance of proper constitutive materials in numerical analysis. As for single-keyed dry joint specimens (NC or SFRC), the 

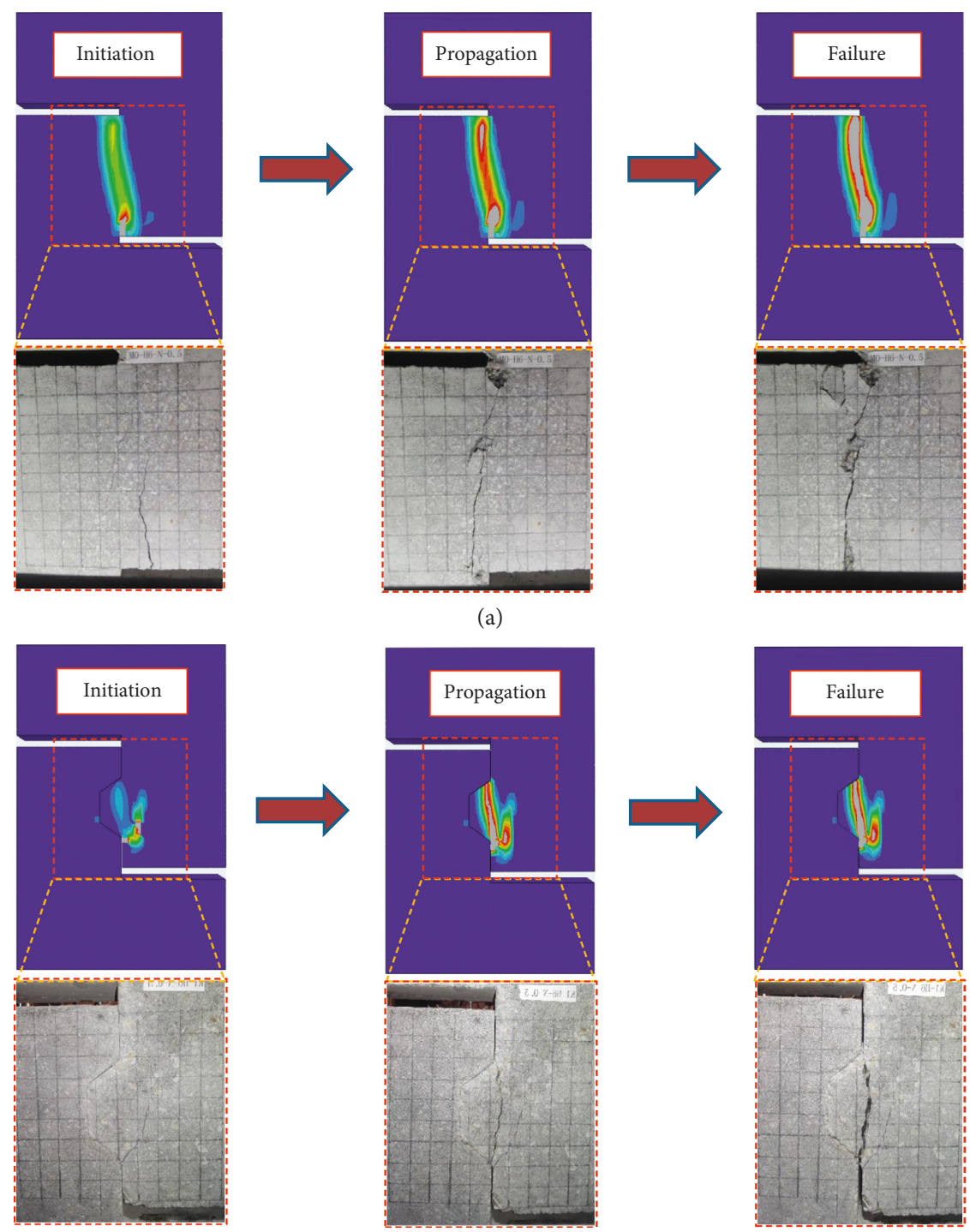

(a)
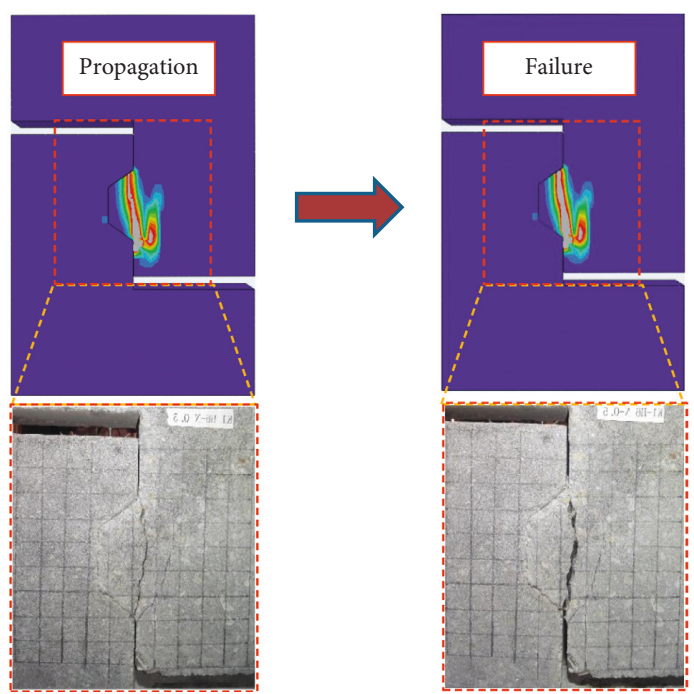

(b)
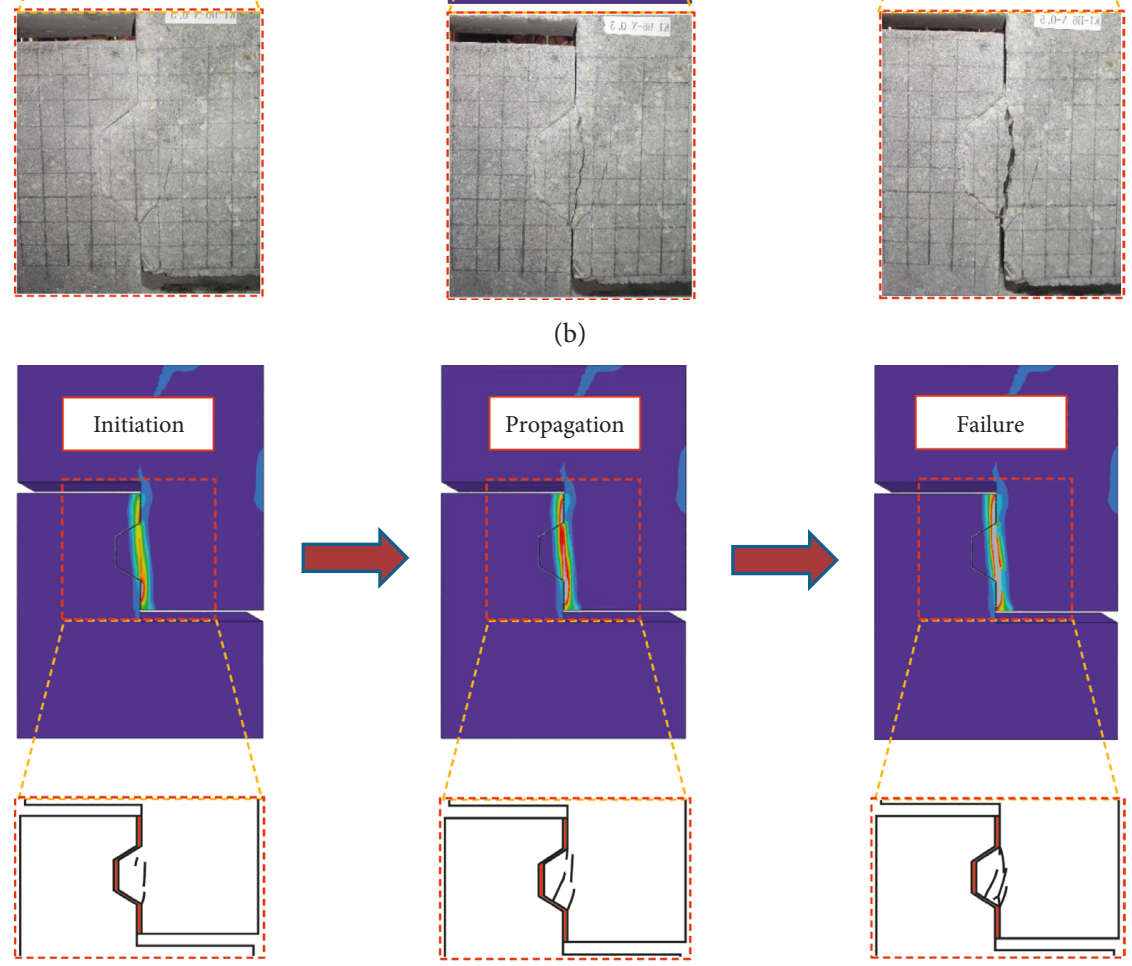

(c)

Figure 5: Comparison of experimental and simulated cracking process for specimens with different joints. (a) Monolithic joint (M0-C500.5). (b) Single-keyed dry joint (K1-C50-0.5). (c) Single-keyed epoxied joint (EA1-C50-3). 
test results were much close to the simulated curves, except for single-keyed dry joint specimens with the confining pressure of 1.0 MPa. The stiffness of the experimental result for K1-C50-1.0 was smaller than that of the numerical result, but the ultimate shear capacities are almost the same. This slight deviation of stiffness may be related to the neglect of brittleness and aggregate interlock effects of concrete.

4.2.2. Portion II: Descending Phase. With the shear failure of the joint, the load dropped suddenly and the fracture ran through the entire joint. Large plastic deformation and material damage were also evident. Especially, due to the limitation of the data acquisition instrument, only the data on ultimate load and the data after sudden dropping of the curve were recorded during the experiments. However, it should be noted that these data points were close to the numerical curve for all types of specimens. Thus, it is acceptable to use the simulated curves to represent the behavior of the descending portion.

4.2.3. Portion III: Residual Phase. After the material destroyed, the capacity of the joint has dropped to a constant value, which was called residual load. At this time, the shear capacity of the joint was mainly provided by the friction action of the shear plane, against the horizontal confining pressure. It can be seen that the numerical results can predict the residual load well.

In general, the experimental data points were distributed near the simulation curve, which indicated that those are in good agreement. The acceptable stiffness deviations in some tests probably resulted from the difference of material properties or the neglect of aggregate interlock effects of concrete under shear action. Furthermore, the unavoidable installation error, quality of models and fabrication technique, rotation of specimens during testing, or even the unfavorable cracking would also affect the validation of the numerical model.

4.3. Comparison of Cracking Process. Figure 5 shows the experimental and simulated cracking process for different joint types of specimens. In this figure, the cracking mode, development of cracking, and failure mode are presented. In order to express the cracking, the area is illustrated in gray where the tension strain has exceeded the ultimate tension strain of concrete.

In Figure 5(a), the cracking process for specimens with monolithic joints (M0-C60-0.5) is analyzed. The gray area initially occurred at the joint bottom and then extended upward to the top. When approaching the ultimate load, the gray area has penetrated the entire shear area, which indicated that the monolithic joint has been completely fractured. This simulated cracking process was consistent with the experimental results, which was shown below the numerical results in the figure.

In Figure 5(b), specimen K1-C50-0.5 was selected to analyze the cracking process of the single-keyed dry joints. Both the numerical and experimental results showed a similar cracking process. The crack (gray area) occurred at the bottom corner of the key at about $45^{\circ}$ with regard to the horizontal direction. As the load continued, a fracture initiated and new cracking appeared at the root of the key, extending upward to the top. Finally, the latter crack penetrated the key so that the joint has been completely sheared off and destroyed. The simulation was consistent with the development of corresponding test for the whole cracking process, including the cracking trend and the value of load at each phase. Particularly, though the corner cracks appeared firstly, they stopped to develop once the new cracks formed in the root area of the key.

In Figure 5(c), the crack initiation and development of single-keyed epoxied joints (EA1-C50-3.0) between experimental and simulated results are compared. The gray area mainly occurred on the bottom corner of the key at first, which indicated that the first crack appeared in this area. This crack extended to the top of the joint as shear load increased. Finally, similar to other types of joints, the crack penetrated the entire key when reaching the ultimate shear capacity. This cracking process also showed high consistency between test and finite element model results.

Generally, it is acceptable to use the numerical method to study the cracking process of all specimens. In experimental investigation, the crack developed rapidly, causing much difficulty to record the whole cracking process in detail. With the finite element model, this deficiency can be eradicated, and it can also comprehensively reveal the phenomenon of crack development.

\section{Extended Parametric Analysis}

As mentioned previously, both the confining pressure and eccentric loads were very important factors that cause the reduction of joint shear resistance. In this part, the influence of lower confining pressure and different loading positions on shear performance of joints was studied through finite element analysis.

5.1. Effect of Lower Confining Pressure. Due to the limitation of experimental investigation, the minimum horizontal confining pressure used in the previous study was generally $0.5 \mathrm{MPa}$ [12]. In this part, the finite element model was used to analyze the shear performance of joints under the confining pressure varying from $0.1 \mathrm{MPa}$ to $0.5 \mathrm{MPa}$.

5.1.1. Shear Capacity and Relative Displacement. The shear capacity and relative displacement for specimens under low horizontal confining pressure (from $0.1 \mathrm{MPa}$ to $0.5 \mathrm{MPa}$ ) are shown in Table 5. To be clear, all the specimens were compared with the corresponding specimens with highest confining pressure $(0.5 \mathrm{MPa})$ in the same series.

For the monolithic joint specimen, when the confining pressure varied from $0.5 \mathrm{MPa}$ to $0.1 \mathrm{MPa}$, the reduction of ultimate load and relative displacement was $6.9 \%$ and $7.2 \%$, respectively. Though both the shear capacity and relative slip decreased with the decrease of the confining pressure at a low level, the effect of the confining stress was not significant. 
TABLE 5: Numerical results for specimens under low horizontal confining stress.

\begin{tabular}{|c|c|c|c|c|c|}
\hline Type of joint & Specimen & Ultimate strength $V_{\mathrm{n} 1}(\mathrm{kN})$ & Slip at ultimate strength $S_{\mathrm{n} 1}(\mathrm{~mm})$ & $V_{\mathrm{n} 1} / V_{0.5}$ & $S_{\mathrm{n} 1} / S_{0.5}$ \\
\hline \multirow{5}{*}{ Monolithic joint (NC) } & M0-C50-0.5 & 165.45 & 0.401 & 1.000 & 1.000 \\
\hline & M0-C50-0.4 & 162.97 & 0.407 & 0.985 & 1.015 \\
\hline & M0-C50-0.3 & 160.57 & 0.401 & 0.971 & 1.000 \\
\hline & M0-C50-0.2 & 160.39 & 0.392 & 0.970 & 0.978 \\
\hline & M0-C50-0.1 & 154.11 & 0.372 & 0.931 & 0.928 \\
\hline \multirow{5}{*}{ Single-keyed dry joint with NC } & K1-C50-0.5 & 96.30 & 0.370 & 1.000 & 1.000 \\
\hline & K1-C50-0.4 & 93.42 & 0.370 & 0.970 & 1.000 \\
\hline & K1-C50-0.3 & 90.33 & 0.358 & 0.938 & 0.968 \\
\hline & K1-C50-0.2 & 86.39 & 0.334 & 0.897 & 0.903 \\
\hline & K1-C50-0.1 & 65.41 & 0.534 & 0.679 & 1.443 \\
\hline \multirow{5}{*}{ Single-keyed dry joint with SFRC } & K1-S50-0.5 & 111.50 & 0.567 & 1.000 & 1.000 \\
\hline & K1-S50-0.4 & 110.71 & 0.587 & 0.993 & 1.035 \\
\hline & K1-S50-0.3 & 107.06 & 0.559 & 0.960 & 0.986 \\
\hline & K1-S50-0.2 & 96.95 & 0.912 & 0.870 & 1.608 \\
\hline & K1-S50-0.1 & 89.09 & 1.181 & 0.800 & 2.083 \\
\hline \multirow{10}{*}{ Single-keyed epoxied joint (NC) } & EA1-C50-0.5 & 258.93 & 0.286 & 1.000 & 1.000 \\
\hline & EA1-C50-0.4 & 249.68 & 0.267 & 0.964 & 0.934 \\
\hline & EA1-C50-0.3 & 244.51 & 0.264 & 0.944 & 0.923 \\
\hline & EA1-C50-0.2 & 231.71 & 0.247 & 0.895 & 0.864 \\
\hline & EA1-C50-0.1 & 223.72 & 0.244 & 0.864 & 0.853 \\
\hline & EC1-C50-0.5 & 247.33 & 0.290 & 1.000 & 1.000 \\
\hline & EC1-C50-0.4 & 239.07 & 0.268 & 0.967 & 0.924 \\
\hline & EC1-C50-0.3 & 231.60 & 0.260 & 0.936 & 0.897 \\
\hline & EC1-C50-0.2 & 217.52 & 0.240 & 0.879 & 0.828 \\
\hline & EC1-C50-0.1 & 213.59 & 0.238 & 0.864 & 0.821 \\
\hline
\end{tabular}

Note: $V_{0.5}$ is the numerical ultimate strength for the same joint type of specimen under $0.5 \mathrm{MPa}$ confining stress; $S_{0.5}$ is the numerical slip at ultimate strength for the same joint type of specimen under $0.5 \mathrm{MPa}$ confining stress; $\mathrm{NC}=$ normal concrete; $\mathrm{SFRC}=$ steel fiber-reinforced concrete.

When the confining pressure decreased from $0.5 \mathrm{MPa}$ to $0.1 \mathrm{MPa}$, the ultimate load for single-keyed dry joint specimens with $\mathrm{NC}$ also decreased. As the confining pressures decreased from $0.5 \mathrm{MPa}$ to $0.2 \mathrm{MPa}$, the reduction of the ultimate load was not significant. However, when the confining pressure was reduced from $0.2 \mathrm{MPa}$ to $0.1 \mathrm{MPa}$, the ultimate load decreased by $32.1 \%$. In addition, when the confining pressure was reduced within the range of $0.5 \mathrm{MPa}$ to $0.2 \mathrm{MPa}$, the relative displacement decreased accordingly, but the magnitude of reduction was not obvious. In contrast, when the horizontal confining pressure was reduced to $0.1 \mathrm{MPa}$, the relative displacement increased by $44.3 \%$, compared with the confining pressure of $0.5 \mathrm{MPa}$.

As for single-keyed dry joint specimens with SFRC at lower confining pressure (0.1 MPa to $0.5 \mathrm{MPa})$, some different conclusions can be drawn. A little reduction of the shear capacity and increase of the relative displacement can be noted. When the confining stress dropped to $0.1 \mathrm{MPa}$ or $0.2 \mathrm{MPa}$, the ultimate load was greatly reduced and the relative slip was increased largely.

As shown in Table 5, the single-keyed epoxied joints with 1 and $3 \mathrm{~mm}$ thickness epoxy are analyzed at different confining pressures from $0.1 \mathrm{MPa}$ to $0.5 \mathrm{MPa}$. The result showed that as the confining pressure decreased, the ultimate load and relative displacement decreased correspondingly. Compared with the confining pressure of $0.5 \mathrm{MPa}$, the reduction of the ultimate load of the singlekeyed epoxied joints with 1 and $3 \mathrm{~mm}$ thickness epoxy was
$13.6 \%$, and the reduction of the relative displacement was $14.7 \%$ and $17.9 \%$, respectively.

5.1.2. Load-Displacement Relationship. The ultimate loaddisplacement curves for specimens at different confining pressures $(0.1 \mathrm{MPa}$ to $0.5 \mathrm{MPa})$ are shown in Figure 6 .

For the monolithic joint, no obvious difference can be seen for different confining pressure specimens. Therefore, it can be considered that the effect of reduction of the confining pressure from $0.5 \mathrm{MPa}$ to $0.1 \mathrm{MPa}$ on the shear performance of monolithic joints is not obvious.

It can be seen from Figure 6(b) that when the confining pressure decreased from $0.5 \mathrm{MPa}$ to $0.2 \mathrm{MPa}$, the other characteristics and trends of the curves remained basically unchanged, except the maximum point and the plateau of the curves decreased correspondingly. However, when the confining pressure was reduced to $0.1 \mathrm{MPa}$, the corresponding curve trends changed largely, and the curves were more fluctuated. The curve had a short plateau before reaching the peak (ultimate load), and it also experienced a plateau before dropping to the stationary stage (residual load).

The ultimate load-displacement curves of single-keyed dry joints with SFRC at different confining pressures (0.1 $\mathrm{MPa}$ to $0.5 \mathrm{MPa}$ ) are shown in Figure 6(c). Similar to the load-slip relationship of single-keyed dry joints with NC, the corresponding curve changed significantly when the confining pressure reduced to $0.2 \mathrm{MPa}$. The slope of the curve 

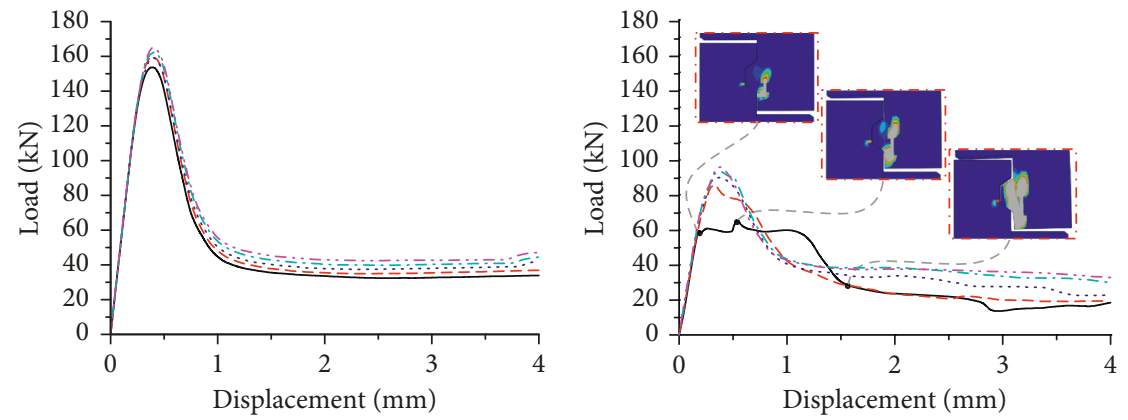

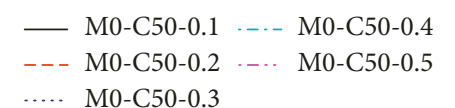

(a)

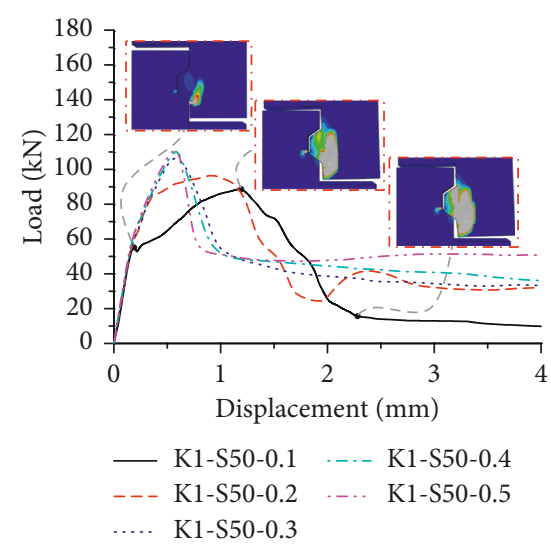

(c)

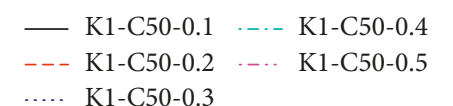

(b)

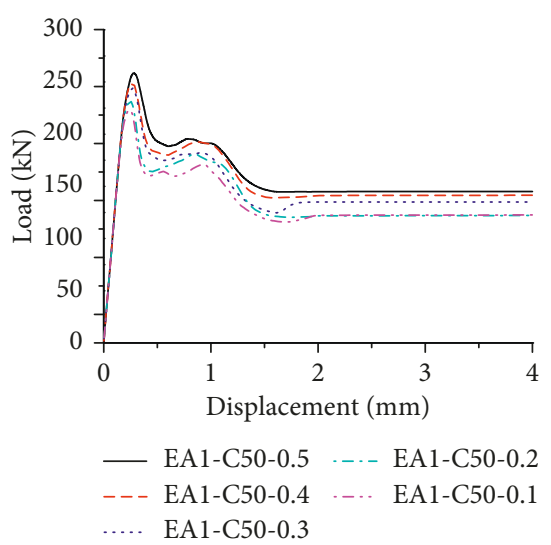

(d)

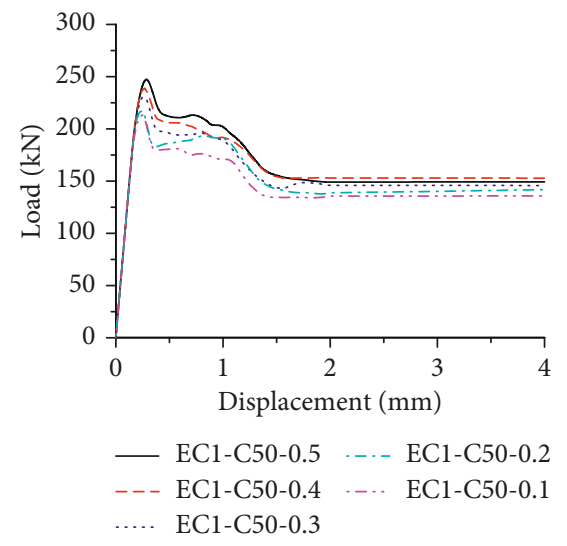

(e)

Figure 6: Load-displacement curves under the confining pressure of 0.5 0.1 MPa. (a) Monolithic joint. (b) Single-keyed dry joint with NC. (c) Single-keyed dry joint with SFRC. (d) $1 \mathrm{~mm}$ thick single-keyed epoxied joint. (e) $3 \mathrm{~mm}$ thick single-keyed epoxied joint.

decreased obviously at the plasticity stage, and the curve became relatively flat after reaching the ultimate load. Therefore, the shear capacity of single-keyed dry joint specimens with SFRC decreased greatly when the confining pressure dropped to $0.2 \mathrm{MPa}$ and $0.1 \mathrm{MPa}$.

For NC single-keyed dry joint specimens with $0.1 \mathrm{MPa}$ confined stress, the unusual phenomenon, as depicted in Figure 6(b), may also be related to the cracking process. The outward slip of the upper male portion resulted in the first constant level of loading. With the increase of vertical load, the sliding friction became large enough to stop the slip. Meanwhile, the bottom corner crack lengthened and widened, causing the slight rotation of the male part. At this time, the ultimate shear strength was reached and the root area of the key started to work. As a result, the key joint shear resistance and rotation existed together, leading to the second plateau. When the key root area cracks linked with each other (penetration), the dropping of the curve 
occurred. This can also be observed in the figure that both the former bottom corner cracks and latter root area cracks lengthened and widened. With the aggregate interlock action along the cracking concrete, the final shear resistance of the keyed joint was maintained at a constant level (residual stage) at last. The cause of abrupt change in SFRC singlekeyed dry joint specimens under low confining stress was similar to that with NC, as depicted in Figure 6(c). The better ductility of SFRC may be the reason for the sustained increase of shear capacity before reaching the peak load.

The ultimate load-displacement curves of single-keyed epoxied joints with 1 and $3 \mathrm{~mm}$ thickness epoxy and regular concrete at different confining pressures $(0.1$ to $0.5 \mathrm{MPa})$ are shown in Figures 6(d) and 6(e). It can be seen that, after reaching the ultimate load, the curve in the descending stage showed fluctuation; that is, the curve first fell rapidly, then had a plateau or a slight rise, and finally descended again to a plateau slowly. It showed that the failure of single-keyed epoxied joints exhibited more ductility under low confining pressures. In addition, it can be clearly seen that all the ultimate load-displacement curves of the model under low confining pressure had a very similar trend. The shear resistance of single-keyed epoxied joints decreased gradually under the low confining pressures from $0.1 \mathrm{MPa}$ to $0.5 \mathrm{MPa}$.

5.2. Effect of Eccentric Loads. As shown in Figure 1, an eccentric moment would exist on the joint, causing the rotation of both the specimen and experimental instrument. Considering the difficulty and safety of the experiment, almost all of the shear tests of joints loaded through the centric line of the top surface. In this part, the finite element model was used to analyze the shear performance of joints under loading with the eccentricity of $0 \mathrm{~mm}$ (centric line loading), $30 \mathrm{~mm}, 60 \mathrm{~mm}$, and $90 \mathrm{~mm}$.

5.2.1. Shear Capacity and Relative Displacement. The shear capacity and relative displacement for specimens under eccentric loads (with the eccentricity from $0 \mathrm{~mm}$ to $90 \mathrm{~mm}$ ) are listed in Table 6. The simulated results were compared with those of the same specimen with centric loads.

Specimen M0-C50-2.0 was chosen as a representative for parametric analysis on eccentric loads of monolithic joints. With the increase of eccentricity, both the ultimate strength and slip at the ultimate strength decreased.

For single-keyed dry joints with NC or SFRC (based on specimens K1-C50-2.0 and K1-S50-2.0), the effect of eccentric load on the shear capacity and relative slip was similar. The farther the loading point away from the centric line, the smaller the ultimate load. On the contrary, the slip at the ultimate strength increased with the increase of eccentricity but leveled off or dropped down at larger eccentric loads.

As for the single-keyed epoxied joint with $\mathrm{NC}$ (based on specimen EA1-C50-2.0), it can be found in Table 6 that the ratio of the corresponding ultimate load of the model with the loading offset of $30 \mathrm{~mm}, 60 \mathrm{~mm}$, and $90 \mathrm{~mm}$ to the ultimate load at the centric line position is $0.787,0.589$, and 0.394 , respectively. This indicated that the shear capacity of epoxied joints decreased with the increase of loading eccentricity, while the slip at the ultimate strength increased with the increase of the eccentricity.

5.2.2. Load-Displacement Relationship. The ultimate loaddisplacement curves for specimens under eccentric loads (with the eccentricity from $0 \mathrm{~mm}$ to $90 \mathrm{~mm}$ ) are shown in Figure 7.

For monolithic joints (M0-C50-2.0), the trend of the load-displacement curve was similar for different loading positions. But the peak load and residual load of joints were lower than those of joints under larger loading eccentricity.

Based on specimen K1-C50-2.0, the load-displacement relationship of single-keyed dry joints with $\mathrm{NC}$ has been studied. The curve changed obviously when the eccentricity was $60 \mathrm{~mm}$ or $90 \mathrm{~mm}$. In this case, the curve has only the ascending and residual phases and no descending phase. Similarly, the single-keyed dry joint specimens with SFRC have two-stage load-slip curves when the eccentric load distance was larger than $30 \mathrm{~mm}$.

This unusual phenomenon may be related to the final failure modes of single-keyed dry joint specimens under different eccentric loads, which are also shown in Figure 7(b). For specimens loaded at the centric line or at the eccentricity of $30 \mathrm{~mm}$, the joints failed in shear of the key. Especially, slight opening of the joint for specimens under less than $30 \mathrm{~mm}$ eccentric loading, resulting from the rotation of the male part, can be observed. This demonstrated that the eccentric loads generated an additional moment, which will counteract the restraint action of horizontal confining pressure. Because of the resistance from horizontal confining pressure, specimens under $30 \mathrm{~mm}$ eccentric loading had a similar load-displacement relationship to those with centric loading. However, when the eccentricity increased to $60 \mathrm{~mm}$ or $90 \mathrm{~mm}$, the moment generated by the eccentric load was large enough to counteract the confine formed by the horizontal restraint force. As a result, the male part slides outwards as a rigid body and the shear capacity of the joint was mainly provided by the friction force. It can also be found in Figure 7(b) that the specimens under $60 \mathrm{~mm}$ or $90 \mathrm{~mm}$ eccentric loading failed in crushing of concrete below the key, and no crack appeared on it.

As for single-keyed epoxied joint specimens, different load-displacement curves can be found for specimens under $60 \mathrm{~mm}$ or $90 \mathrm{~mm}$ eccentric loading. After reaching the peak load, the shear capacity decreased slightly. With the increase of displacement, the load rose again or even exceeded the initial peak value. Finally, the shear capacity of joints decreased slowly.

For this different curve characteristic of single-keyed epoxied joint specimens under larger eccentric compression, it may be related to the cracking process. The cracking process of single-keyed epoxied joint specimens at the loading eccentricity of $90 \mathrm{~mm}$ is also shown in Figure $7(\mathrm{~d})$. When the eccentric load is applied, additional moment will generate on the top area of the joint. Due to the cohesion of epoxy, tensile cracks were formed in this area but without the joint opening. Then, the crack developed downwards 
TABLE 6: Numerical results for specimens at different loading positions.

\begin{tabular}{|c|c|c|c|c|c|c|}
\hline Type of joint & Specimen & $\begin{array}{l}\text { Loading position (mm) } \\
\text { (deviation from midpoint) }\end{array}$ & $\begin{array}{l}\text { Ultimate strength } \\
V_{\mathrm{n} 2}(\mathrm{kN})\end{array}$ & $\begin{array}{l}\text { Slip at ultimate } \\
\text { strength } S_{\mathrm{n} 2}(\mathrm{~mm})\end{array}$ & $V_{\mathrm{n} 2} / V_{0}$ & $S_{\mathrm{n} 2} / S_{0}$ \\
\hline \multirow{4}{*}{ Monolithic joint (NC) } & M0-C50-2.0(0) & 0 & 200.92 & 0.499 & 1.000 & 1.00 \\
\hline & M0-C50-2.0(30) & 30 & 181.37 & 0.519 & 0.903 & 1.04 \\
\hline & M0-C50-2.0(60) & 60 & 130.69 & 0.451 & 0.650 & 0.90 \\
\hline & M0-C50-2.0(90) & 90 & 80.36 & 0.365 & 0.400 & 0.73 \\
\hline \multirow{4}{*}{ Single-keyed dry joint with NC } & K1-C50-2.0(0) & 0 & 141.33 & 0.489 & 1.000 & 1.00 \\
\hline & K1-C50-2.0(30) & 30 & 95.92 & 0.504 & 0.679 & 1.03 \\
\hline & K1-C50-2.0(60) & 60 & 60.67 & 0.668 & 0.429 & 1.37 \\
\hline & K1-C50-2.0(90) & 90 & 42.23 & 0.661 & 0.299 & 1.35 \\
\hline \multirow{4}{*}{ Single-keyed dry joint with SFRC } & K1-S50-2.0(0) & 0 & 162.71 & 0.629 & 1.000 & 1.00 \\
\hline & $\mathrm{K} 1-\mathrm{S} 50-2.0(30)$ & 30 & 97.91 & 0.585 & 0.602 & 0.93 \\
\hline & K1-S50-2.0(60) & 60 & 60.80 & 0.796 & 0.374 & 1.27 \\
\hline & $\mathrm{K} 1-\mathrm{S} 50-2.0(90)$ & 90 & 42.23 & 0.638 & 0.260 & 1.01 \\
\hline \multirow{4}{*}{ Single-keyed epoxied joint (NC) } & EA1-C50-2.0(0) & 0 & 414.00 & 0.447 & 1.000 & 1.00 \\
\hline & $\begin{array}{c}\text { EA1-C50- } \\
2.0(30)\end{array}$ & 30 & 326.00 & 0.518 & 0.787 & 1.16 \\
\hline & $\begin{array}{c}\text { EA1-C50- } \\
2.0(60)\end{array}$ & 60 & 244.00 & 0.898 & 0.589 & 2.01 \\
\hline & $\begin{array}{c}\text { EA1-C50- } \\
2.0(90)\end{array}$ & 90 & 163.00 & 0.994 & 0.394 & 2.22 \\
\hline
\end{tabular}

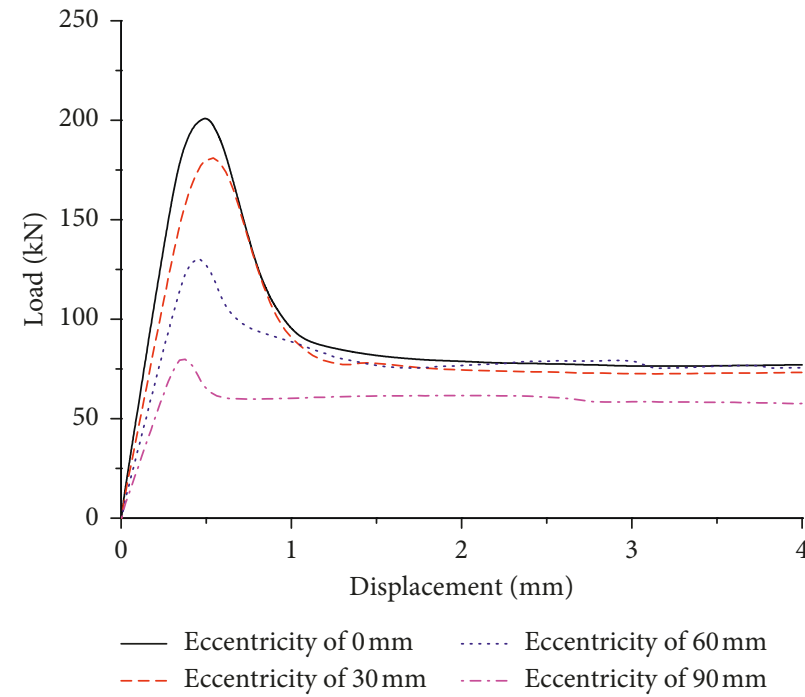

(a)

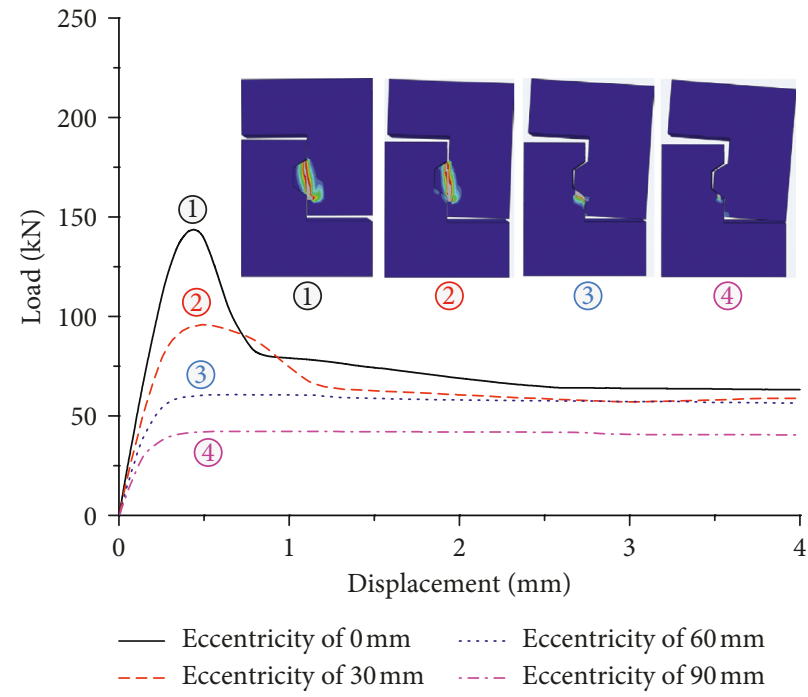

(b)

Figure 7: Continued. 


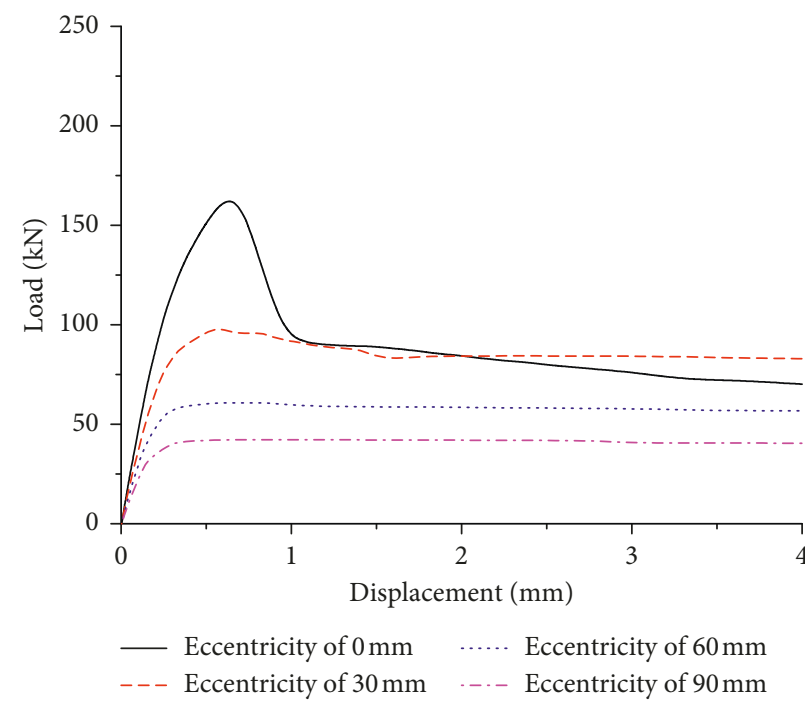

(c)

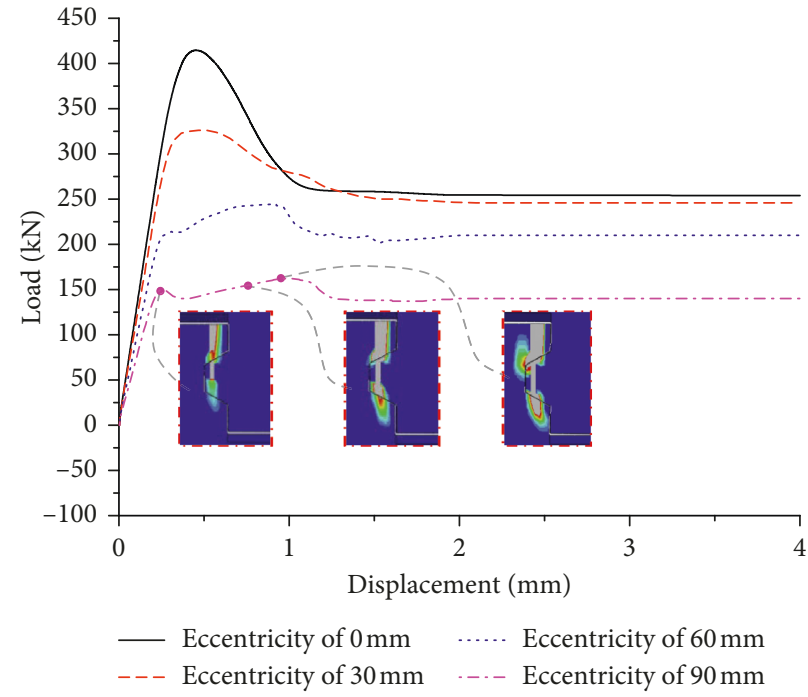

(d)

Figure 7: Typical load-displacement curves for specimens at different loading positions. (a) Monolithic joint with NC. (b) Single-keyed dry joint with NC. (c) Single-keyed dry joint with SFRC. (d) Single-keyed epoxied joint with NC.

and began to generate in the key. When the key was penetrated by the crack, the curve reached the first peak load. At this time, the key was sheared off and the tensile stress was redistributed, causing the slight decrease of the load-displacement curve. As the crack developed toward the bottom of the joint, the curve rose slowly. When reaching the ultimate shear capacity, the crack penetrated the entire joint, but no any damage can be seen in the epoxy layer. Thus, it can be found that, under large eccentric loads, the breaking of the single-keyed epoxied joint was from the top to the bottom. At the final residual stage, the shear capacity of the joint may be related to the friction between cracked concrete surfaces under confining pressure.

\section{Comparison of the Simulated Results with AASHTO Provision}

Currently, the calculation of shear capacity of the dry joint in design was usually based on the provision in the AASHTO 2003 specification. This equation was computed as a function of the root area of the key $A_{\mathrm{k}}\left(\mathrm{m}^{2}\right)$, the cylinder compressive strength of the male part $f_{\mathrm{c}}^{\prime}(\mathrm{MPa})$, the horizontal confining pressure $\sigma_{\mathrm{n}}(\mathrm{MPa})$, and the area of the friction contact on the joint surface $A_{\mathrm{sm}}\left(\mathrm{m}^{2}\right)$ :

$$
V_{\mathrm{f}}=A_{\mathrm{k}} \sqrt{f_{\mathrm{c}}^{\prime}}\left(0.9961+0.2048 \sigma_{\mathrm{n}}\right)+0.6 A_{\mathrm{sm}} \sigma_{\mathrm{n}} .
$$

The comparison of the AASHTO design formula with the parametric analysis results is listed in Table 7. For this table, the average values of $V_{\mathrm{a}} / V_{\mathrm{s}}$ for $\mathrm{NC}$ specimens or SFRC specimens were 0.89 and 0.77 , respectively. This result indicated that the formula of AASHTO 2003 specification underestimated the ultimate loads of single-keyed dry joints under low confining pressure for both NC and SFRC. On the contrary, the values of $V_{\mathrm{a}} / V_{\mathrm{s}}$ for NC specimens were always larger than those for fiber-reinforced concrete specimens. This highlighted the necessity of considering the concrete type in joint design.

Table 7 also shows the comparison between the AASHTO results and simulated results of single-keyed dry joint specimens under eccentric loading. It can be seen that the AASHTO formula overestimated the ultimate shear capacity of single-keyed dry joints for either NC or SFRC. Since the AASHTO formula neglected the influence of loading position on the joints, the calculated ultimate load was the same for the identical specimen under different eccentric loading. However, the ultimate load of the model was reduced due to the local bending moment caused by eccentric loading in the simulation, resulting in a smaller ultimate load than that estimated by the AASHTO formula. In order to draw a reliable and reasonable conclusion, more experimental results should also be considered. In general, the AASHTO formula should be reduced when calculating the shear capacity of single-keyed dry joints under an eccentric load.

\section{Conclusion}

In this paper, the numerical simulations were performed to study the effect on shear behavior of different single-keyed joints in PCSBs by extended parameters of low confining pressure and eccentric loads. Based on the simulation results, the main conclusions were drawn as follows:

(1) Simulated ultimate shear capacity, load-displacement curve, and cracking process for monolithic joint, single-keyed dry joint, and single-keyed epoxied joint specimens were in good agreement with the experimental results. This indicated that the proposed finite element model may be able to predict accurately the shear behavior of these joints. 
TABLE 7: Comparison of current provisions with parametric analysis results.

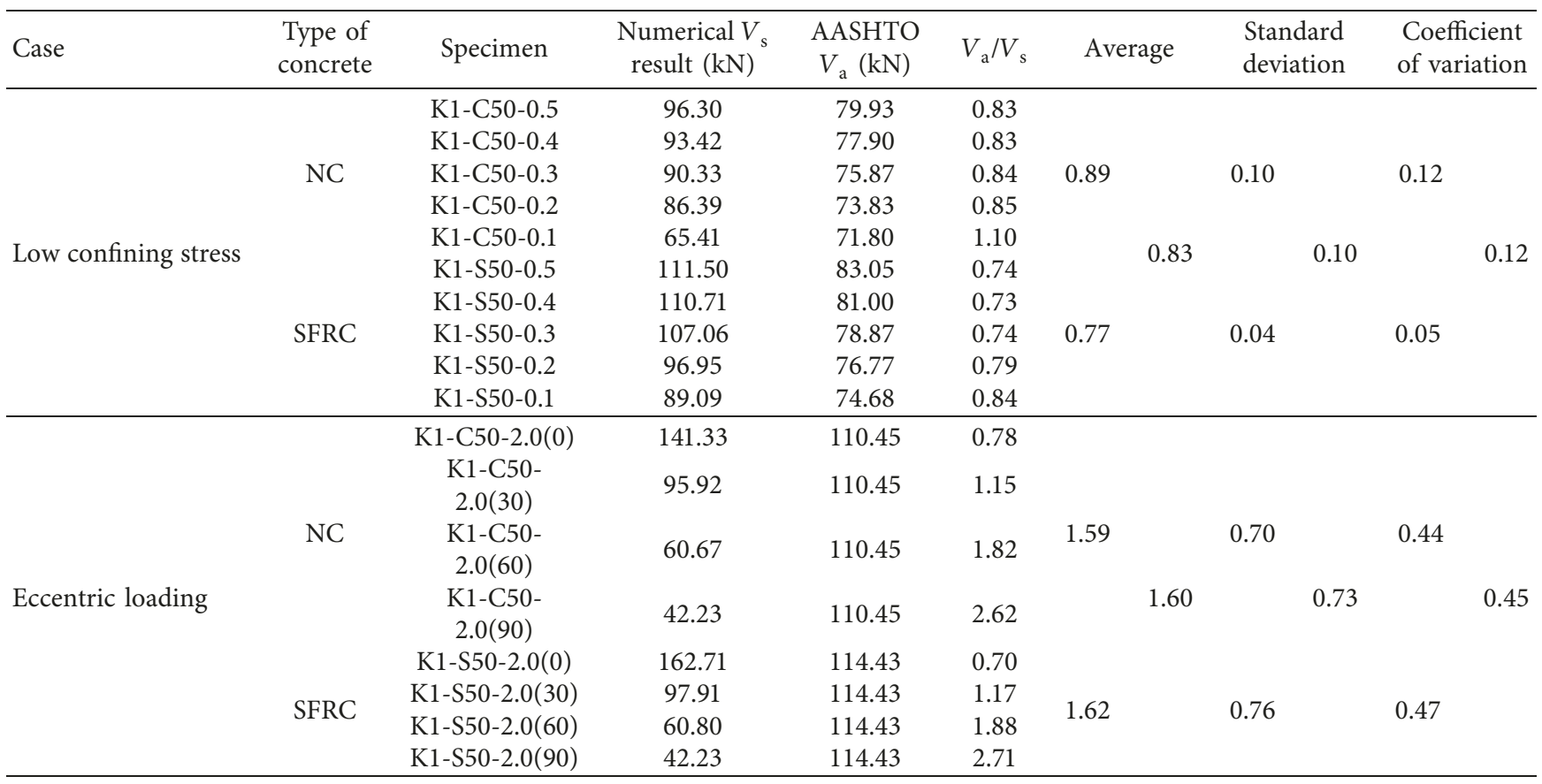

Note: $\mathrm{NC}=$ normal concrete; $\mathrm{SFRC}=$ steel fiber-reinforced concrete.

(2) For lower horizontal confining pressures, the decrease of confining pressure (from $0.5 \mathrm{MPa}$ to $0.1 \mathrm{MPa}$ ) has a little influence on the shear capacity of monolithic joint specimens (7.2\%) and single-keyed epoxied joint specimens (13.6\%), but significant decrement can be noted for single-keyed dry joints with NC (32.1\%) and with SFRC (20.0\%).

(3) Similar load-displacement relationship can be seen for monolithic joint specimens or single-keyed epoxied joint specimens when the confining pressure reduced from $0.5 \mathrm{MPa}$ to $0.1 \mathrm{MPa}$, while a large change in the load-displacement relationship can be observed for single-keyed dry joint specimens with $\mathrm{NC}$ or SFRC for $0.2 \mathrm{MPa}$ confining pressure.

(4) The reduction of the shear capacity was obvious for different types of specimens with increasing loading eccentricity. For the eccentricity larger than $60 \mathrm{~mm}$, an obvious change of the load-slip curve can be seen in single-keyed specimens.

(5) The AASHTO formula underestimated the shear capacity of specimens under lower confining pressure (average $V_{\mathrm{a}} / V_{\mathrm{s}}$ of 0.83 ) but overestimated the shear capacity of joints at eccentric loads (average $V_{\mathrm{a}} / V_{\mathrm{s}}$ of 1.60). On the contrary, the AASHTO formula neglects the influence of concrete type, while it has been proved to be a vital variable. Thus, it is suggested that the AASHTO design code should consider the effect of eccentric load and concrete type.

\section{Data Availability}

The data used to support the findings of this study are available from the corresponding author upon request.

\section{Conflicts of Interest}

The authors declare that there are no conflicts of interest for this article.

\section{Acknowledgments}

This research was funded by the National Natural Science Foundation of China (51778150), Natural Science Foundation of Guangdong Province, China (2016A030313699), and Science and Technology Planning Project of Guangzhou City (201804010422). The authors gratefully acknowledge these generous supports.

\section{References}

[1] K. Koseki and J. E. Breen, "Exploratory study of shear strength of joints for precast segmental bridges," Research Report, Center for Transportation Research, The University of Texas at Austin, Austin, TX, USA, 1983.

[2] M. M. Bakhoum, Shear Behavior and Design of Joints in Precast Concrete Segmental Bridges, Massachusetts Institute of Technology, Cambridge, MA, USA, 1990.

[3] A. C. Aparicio, G. Ramos, and J. R. Casas, "Testing of externally prestressed concrete beams," Engineering Structures, vol. 24, no. 1, pp. 73-84, 2002.

[4] H. B. Jiang, L. Chen, Z. Ma, and W. Feng, "Shear behavior of dry joints with castellated keys in precast concrete segmental bridges," Journal of Bridge Engineering, vol. 20, no. 2, article 04014062, 2002.

[5] X. M. Zhou and N. Mickleborough, "Shear strength of joints in precast concrete segmental bridges," ACI Strctural Journal, vol. 102, no. 1, pp. 901-904, 2005.

[6] J. Turmo, G. Ramos, and A. C. Aparicio, "Shear strength of dry joints of concrete panels with and without steel fibres," Engineering Structures, vol. 28, no. 1, pp. 23-33, 2006. 
[7] T. H. Kim, Y. J. Kim, B. M. Jin, and H. M. Shin, "Numerical study on the joints between precast post-tensioned segments," International Journal of Concrete Structures and Materials, vol. 19, pp. 3-9, 2007.

[8] M. Alcalde, H. Cifuentes, and F. Medina, "Influencia del número de llaves en la resistencia a cortante de juntas secas postensadas," Materiales de Construcción, vol. 63, no. 310, pp. 297-307, 2013.

[9] R. Shamass, X. M. Zhou, and Z. Wu, "Numerical analysis of shear-off failure of keyed epoxied joints in precast concrete segmental bridges," Journal of Bridge Engineering, vol. 22, no. 1, article 04016108, 2007.

[10] R. Shamass, X. M. Zhou, and G. Alfano, "Finite-element analysis of shear-off failure of keyed dry joints in precast concrete segmental bridges," Journal of Bridge Engineering, vol. 20, no. 6, article 04014084, 2005.

[11] M. Alcalde, H. Cifuentes, and F. Medina, "Shear strength of dry keyed joints and comparison with different formulations," in Proceedings of the 8th International Conference on Fracture Mechanics of Concrete and Concrete Structures, Toledo, Spain, March 2013.

[12] H. B. Jiang, T. L. Wang, and J. X. Xiao, "Shear behavior of dry joints in precast steel fiber reinforced concrete segmental bridges," China Journal of Highway and Transport, vol. 31, no. 12, pp. 1-13, 2018.

[13] GB 50010-2010, Code for Design of Concrete Structures, China Academy of Building Research, Beijing, China, 2010.

[14] X. Ning and Y. Ding, "Effect of steel fiber on the damage constitutive model of concrete under uniaxial compression," Journal of Building Materials, vol. 18, no. 2, pp. 214-220, 2015. 


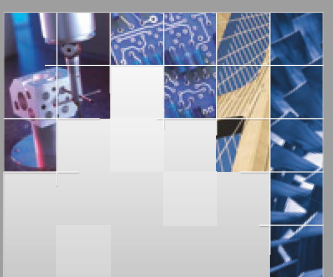

\section{Enfincering}
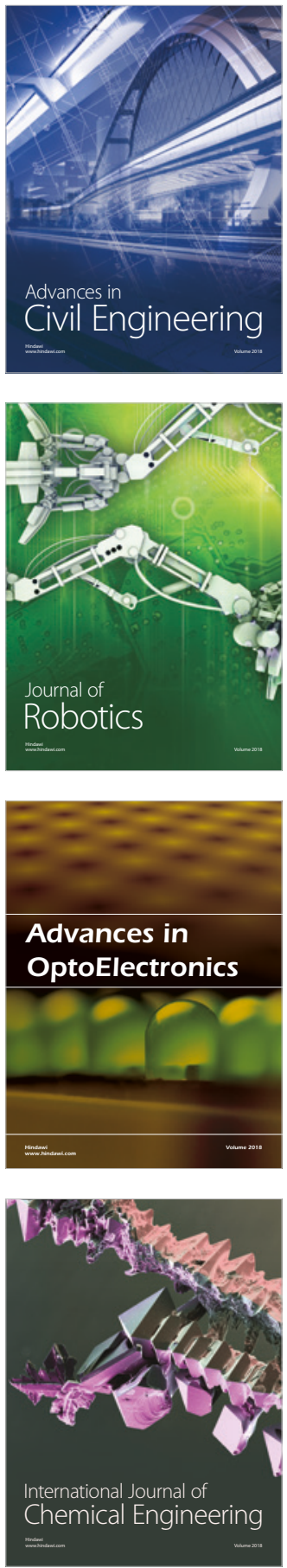

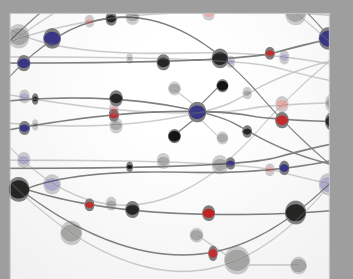

\section{Rotating \\ Machinery}

The Scientific World Journal

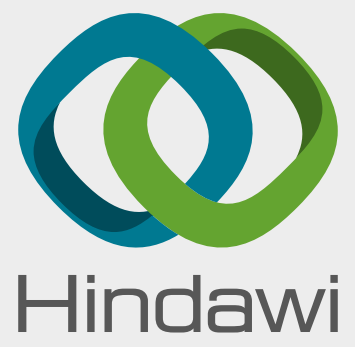

Submit your manuscripts at

www.hindawi.com
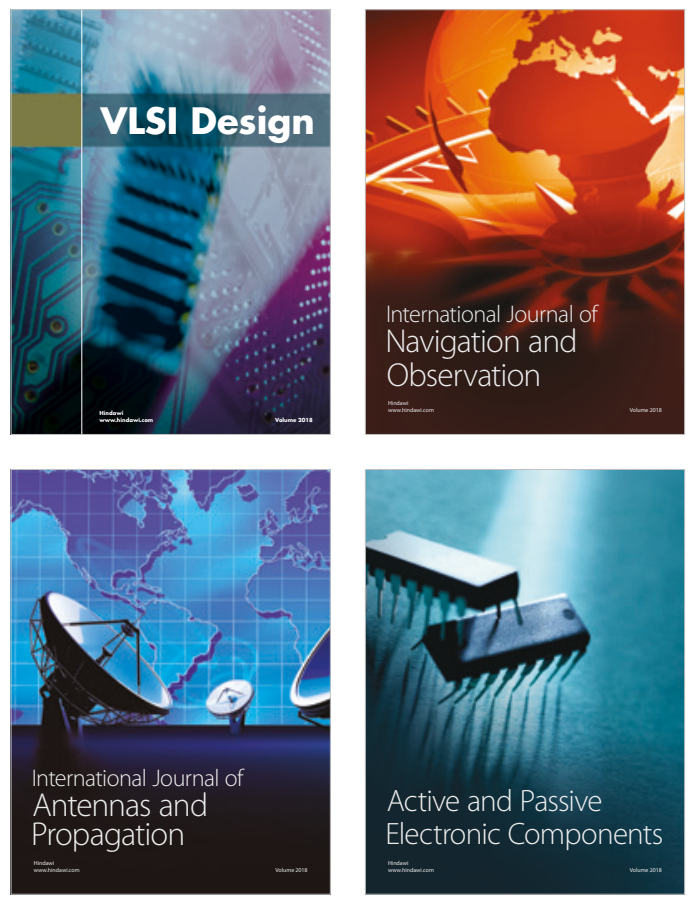
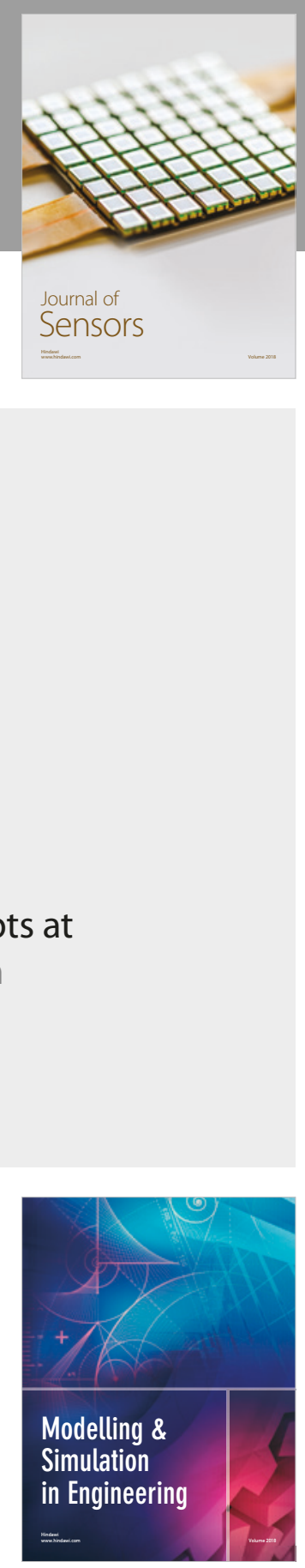

\section{Advances \\ Multimedia}
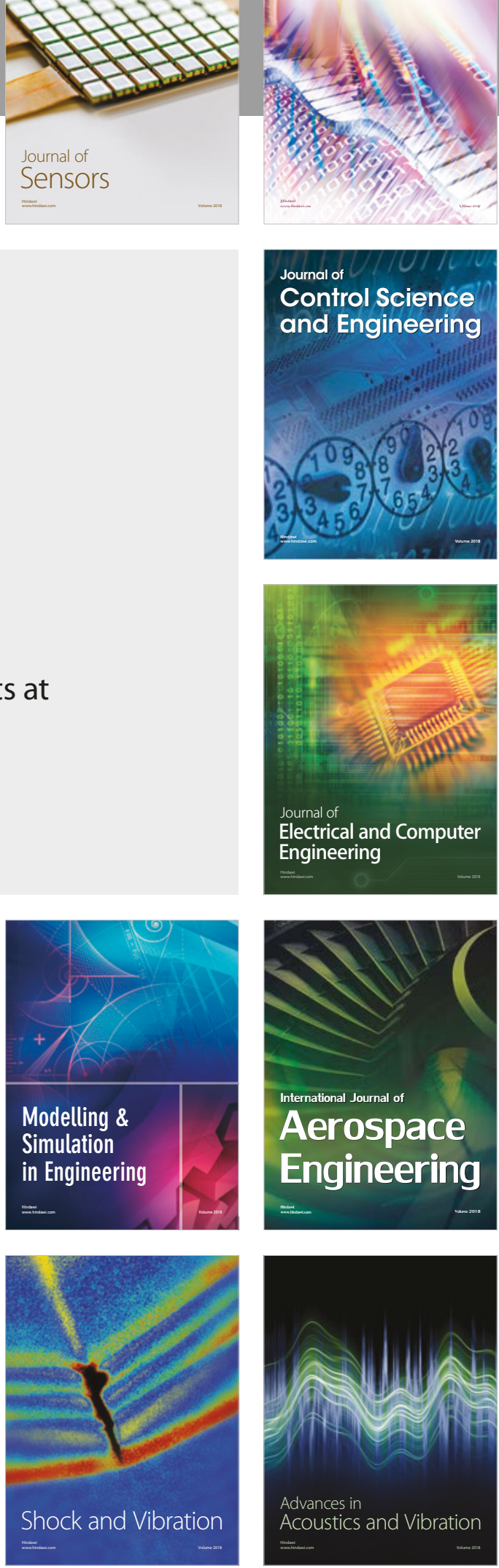